\title{
Neuromodulation of bone: Role of different peptides and their interactions (Review)
}

\author{
XIAOYU WANG, JIA XU and QINGLIN KANG \\ Department of Orthopedic Surgery, Shanghai Jiao Tong University Affiliated \\ Sixth People's Hospital, Shanghai 200233, P.R. China \\ Received May 4, 2020; Accepted September 18, 2020
}

DOI: $10.3892 / \mathrm{mmr} .2020 .11670$

\begin{abstract}
Our understanding of the skeletal system has been expanded upon the recognition of several neural pathways that serve important roles in bone metabolism and skeletal homeostasis, as bone tissue is richly innervated. Considerable evidence provided by in vitro, animal and human studies have further elucidated the importance of a host of hormones and local factors, including neurotransmitters, in modulating bone metabolism and osteo-chondrogenic differentiation, both peripherally and centrally. Various cells of the musculoskeletal system not only express receptors for these neurotransmitters, but also influence their endogenous levels in the skeleton. As with a number of physiological systems in nature, a neuronal pathway regulating bone turnover will be neutralized by another pathway exerting an opposite effect. These neuropeptides are also critically involved in articular cartilage homeostasis and pathogenesis of degenerative joint disorders, such as osteoarthritis. In the present Review, data on the role of several neuronal populations in nerve-dependent skeletal metabolism is examined, and the molecular events involved are explored, which may reveal broader relationships between two apparently unrelated organs.
\end{abstract}

\section{Contents}

1. Introduction

2. Neuropeptides of the sensory nervous system

3. Neuropeptides of the sympathetic nervous system (SNS)

4. Semaphorin $3 \mathrm{~A}$ in bone and cartilage metabolism

Correspondence to: Professor Qinglin Kang or Dr Jia Xu, Department of Orthopedic Surgery, Shanghai Jiao Tong University Affiliated Sixth People's Hospital, 600 Yishan Road, Shanghai 200233, P.R. China

E-mail: orthokang@163.com

E-mail:xujia0117@126.com

Key words: mesenchymal stem cells, substance $\mathrm{P}$, calcitonin gene-related peptide, neuropeptide $\mathrm{Y}$, norepinephrine, $\beta$-adrenergic receptor
5. Comprehensive description of leptin in bone and cartilage metabolism

6. Schwann cells and neurotrophic factors in bone metabolism

7. Summary

\section{Introduction}

The skeletal system serves as the most important weight-bearing tissue; each bone undergoes a process of differentiation through various progenitor and precursor stages (1). Despite the beneficial effects of free vascularized bone grafts in treating large bone defects, impaired bone quality and postoperative osteoporosis may hinder the outcome of reconstructive surgery (2). A higher degree of osteogenesis has been observed in engineered vascularized and neurotized engineered bone tissue with a sensory nerve or vascular bundle implanted (3). Application of vascularized iliac flaps with simultaneous neurorrhaphy between ilioinguinal nerve and inferior alveolar nerve may also effectively prevent bone resorption of grafts in mandible reconstruction and improve the quality of dental implants (4). Of note, fractures combined with craniocerebral or spinal cord injuries often recover much more rapidly compared with those without neuronal injury (5). Previous studies have outlined the expression of certain neuropeptides on bone cells as well as chondrocytes, indicating a local neuropeptide microenvironment that may function as a mediator to relay physiological signals to the bone cells nearby (6-9). These neural pathways are well-appreciated factors involved in paracrine/autocrine and immunoregulatory processes that control vascularization and matrix deposition during skeletal growth.

Peripheral and central nerves are two major components that constitute a functional neural system. An increasing number of studies have reported that sensory innervation in the peripheral nervous system (PNS) is one of the key factors in skeletal physiology and pathological metabolism $(8,10,11)$. Sensory neurotransmitters, such as calcitonin gene-related peptide (CGRP) and substance $\mathrm{P}$ (SP), participate in angiogenesis, nociceptive transmission and inflammation during bone turnover (11-15). Sympathetic nerves are important components of the PNS that are involved in the proliferation and differentiation of various skeletal cells through the activation of adrenoreceptors and neuropeptide Y (NPY) receptors signaling (16-19). Semaphorins influence bone and cartilage 
metabolism by acting as sensory and sympathetic nerve-specific axon guidance molecules $(20,21)$. Some neural signals, such as NPY and leptin, not only have direct effects on osteoblasts and chondrocytes, but also influence bone and cartilage indirectly through the central nervous system (CNS) (22-24). Neuroglial cells serve indispensable roles in peripheral tissue regeneration, with various neurotrophic factors involved (25-27). Novel insights into the influence of certain neuromodulators are yet to be summarized. In the present article, the research progress made in this field is reviewed with an aim to elucidate the influence of major neuropeptides from the PNS and the CNS related to bone turnover, cartilage physiology and pathophysiology, the neuropharmacological potential in treating skeletal disorders and the interaction among these molecules.

\section{Neuropeptides of the sensory nervous system}

Sensory nerve fibers are distributed near blood vessels targeting the bone marrow and periosteum, as well as cortical and trabecular bone structures $(6,7,28)$. Among these compartments, sensory fibers are distributed at a higher density in the epiphysis compared with the metaphysis, and are mostly confined to vascularized CD $31^{+}$Haversian canals (6). In the following subsections, the roles of SP and calcitonin gene-related peptide in skeletal modulation are reviewed.

SP in bone metabolism. SP is a member of the mammalian tachykinin family; it serves important roles in numerous biological processes related to pain transmission, neurogenic inflammation and contraction of smooth muscle through neurokinin (NK)-1, NK-2 and NK-3 receptors on target tissue (29). SP-positive nerve fibers are widely distributed in various bone tissues, especially in metabolically active parts, such as the periosteum and the epiphyseal growth plate; cartilage membranes and chondrocytes have also been found to be SP-positive (30-32).

Study of SP expression during callus differentiation in adult mice has revealed its crucial role during the physiological process of fracture healing. Increased SP staining was observed in the affected tissue region shortly after fracture in wild-type (WT) mice. A compromised fracture healing process as well as the altered biomechanical performance of the non-fractured leg was found in SP-deficient mice (8). An in vitro study showed that SP interacts with the NK-1 receptor (NK-1R) expressed on bone marrow stromal cells in a dose-dependent manner (33); NK-1 activation increases alkaline phosphatase (ALP) activity and upregulates runt-related transcription factor (Runx2) protein expression levels at low concentrations, but induces enhanced mineralization and proliferation at high concentrations in the context of bone marrow stromal cell differentiation. The downstream Wnt/ $\beta$-catenin signaling pathway is considered to be involved in this process (33). Mei et al (34) reported an upregulation of osteoblast markers (collagen type I, ALP, osteocalcin and Runx2) and elevation of mRNA expression levels of c-myc, cyclin D1 and lymphocyte enhancer factor-1 in the MC3T3-E1 osteoblastic cell line. Such bone morphogenetic protein 2 (BMP2)-mediated effects may be attenuated by another sensory neuropeptide, CGRP. In an in vitro study of $\mathrm{C} 2 \mathrm{C} 12$ myoblasts and MC3T3 pre-osteoblasts, bone differentiation induced by downregulated BMP2 was observed when the cells were co-stimulated with SP and CGRP (35). The MAPK signaling pathway was speculated to be a potential convergence of the negative feedback mechanism between these two sensory neuropeptides, in accordance with another finding that CGRP attenuates MAPK signaling and decreases TGF- $\beta 1$-induced hepatic plasminogen activator inhibitor-1 mRNA expression in HepG2 human liver cancer cells $(35,36)$. Goto et al (37) observed that addition of SP to the cell culture medium could stimulate the expression of osteocalcin, Runx2 and collagen I in late-stage osteogenesis, but not in the early differentiation stage. Thus, it was concluded an osteogenic effect of SP on more mature osteoblast cells compared with on pre-osteoblastic cells. Apart from its role in regulating bone metabolism in vitro and in vivo, SP also promotes cell mobilization in the periphery. Hong et al (38) first revealed that SP could induce the mobilization of clusters of CD29+ stromal-like cells from bone marrow into the periphery. Based on that study, Um et al (39) reported an increase in the number of circulating endothelial progenitor cells in the peripheral blood and of CD31 $1^{+}$cells (which were related to angiogenic activity) in Matrigel plugs following subcutaneous injection of SP. Study of the BMSC-like ST2 cells revealed that N-cadherin as well as extracellular-signal-regulated-kinase (ERK) and protein kinase B (Akt) were involved in the mechanisms responsible for chemotactic migration in response to SP (40). Focal adhesion kinase may act downstream of PI3K/Akt in this process, which points to potential mechanisms underlying the association between angiogenesis and MSC migration during osteogenesis $(12,40)$.

Catabolic effects of SP in bone metabolism have also been observed. Sohn (41) determined that SP could stimulate bone resorption via activation of the NF-kB pathway in osteoclast precursors, which corresponds to the reduced bone resorption rate with high apoptosis level of osteoclasts in tachykinin precursor 1 (Tac1)-deficient mice identified in another study (8). Such osteoclastic effect is inhibited by hemokinin-1, a member of the tachykinin family that shares the same receptor (NK-1R) with $\mathrm{SP}$, indicating a negative feedback mechanism through which compensatory responses are initiated to counteract SP upregulation (42). Different functions of SP during osteogenesis may be related to the concentration of neuropeptides and the timeline of exposure. Although $\mathrm{SP}$ can directly activate receptor activator of $\mathrm{NF}-\kappa \mathrm{B}$ ligand (RANKL)-induced macrophage osteoclastogenesis and facilitate $\mathrm{NF}-\kappa \mathrm{B}$ signaling in bone marrow-derived macrophages (BMMs) in vitro, the concentration of RANKL is usually too low to evoke bone resorption processes $(8,33)$. Based on these data, it is certain that the effect of SP on bone metabolism depends on whether its level is greater or less than a specific range. Further research is still required, however, to further understand the full dose-response relationship between SP and the equilibrium of bone resorption and formation.

CGRP in bone metabolism. CGRP is a nociceptive neurotransmitter released from capsaicin-sensitive sensory nerves in response to various stimulations $(6,13,43)$. The CGRP receptor complex contains the calcitonin receptor-like receptor and its co-receptor, receptor activity modifying protein 1 (RAMP1); expression of these receptor complexes have been demonstrated on osteoclasts, osteoblasts and their precursors, and 
BMMs (44-46). Although the distribution of CGRP positive fibers in skeleton is similar to that of SP (7), they do not exert similar functions in bone metabolism. There is a consensus that CGRP exerts an inhibitory influence on osteoclastogenesis. Wang et al (44) demonstrated that CGRP could inhibit bone resorption activity at a concentration of $10^{-8} \mathrm{mmol} / \mathrm{l}$ by suppressing the activation of RANKL and downregulating tartrate-resistant ALP and cathepsin K, two marker genes for mature osteoclasts (1). CGRP promotes the proliferation and osteogenic activity of both osteoblasts and their precursor cells in a dose-dependent manner, as observed in primary osteoblastic cells isolated from the calvaria of newborn rabbits, by increasing the levels of intracellular cAMP and upregulating expression of activating transcription factor (45). The Hippo/Yap pathway is also involved in the osteogenic phenotype mediated by the G-protein coupled receptor RAMP1 (46). Coupling with osteogenesis, CGRP exerts an angiogenic effect in the early stage during bone regeneration and ischemia, partly due to its vasodilator capacity and stimulation of endothelial cell migration $(11,47)$.

The cellular mechanism has been further studied in a coculture system containing dorsal root ganglia (DRG) and MSCs in which the mRNA expression levels of stemness-related genes (Sox2, Nanog and Oct4) were upregulated and, more importantly, the basal rate of autophagy in BMSCs was improved through enhanced signaling of the AMP-activated protein kinase/mTOR pathway (48). As DRG cells contain both capsaicin-sensitive sensory neurons and Schwann cells, this result reveals a new perspective on the relationship between nerve and bone tissue. A study in 2010 reported the inhibitory effect of CGRP on angiotensin II-induced endothelial progenitor cells senescence by enhancing klotho (a novel 'anti-aging' membrane-bound protein) expression and suppressed the production of NADPH oxidase and reactive oxygen species (ROS), which delayed the senescence and dysfunction of endothelial progenitor cells in hypertension (49). As a functional and intact endothelium during vascularization is closely related to bone remodeling, CGRP may act as an endogenous protective substance by scavenging ROS and maintaining homeostasis of intraosseous cells.

Bone remodeling is closely linked to the surrounding inflammatory activities $(50,51)$. Lipopolysaccharide (LPS) has negative effects on the differentiation and proliferation of osteoblasts (51). CGRP reduces Porphyromonas gingivalis LPS-induced cytostatic activity and apoptosis in osteoblasts via decreasing the expression of c-Caspase-3 and c-Caspase-8. CGRP also exerts a protective effect on osteoblasts by the suppression of TNF- $\alpha$ (52). Macrophages are immune-reactive cells that participate in the inflammatory response in tissue repairing (53). Duan et al (14) have demonstrated that exogenous CGRP attenuates LPS-induced acute lung injury by promoting the expression of markers of M2 macrophages (IL-10, Fizz 1 and mannose receptor $\mathrm{C}$ type 1 ) in primary murine peritoneal macrophages. The underlying mechanism of macrophage polarization toward M2 is partially through calmodulin, protein kinase $\mathrm{C}$ and protein kinase A pathways (14). Similarly, SP administration in mice alleviates progression of rheumatoid arthritis symptoms and leads to the induction of M2 type macrophages in circulation (54). SP can also activate bone marrow-derived monocytes into phagocytic M2 like macrophages through direct activation of the PI3K/Akt/mTOR pathway and improve functional recovery after spinal cord injury (15). At present, there is limited literature that describes the role of sensory neuropeptides in modulating macrophage polarization. Further characterization of the interplay between sensory neuropeptides and macrophage will give useful hint for understanding their functions during osteogenesis and vascularization.

Previous studies have demonstrated the role of the sensory peptides in the pathogenesis of osteoporosis, a critical risk factor for fragility fractures, especially in the elderly and postmenopausal women. Ovariectomy of adult female mice reduces SP in the bone and leads to osteoporosis (55). Inhibition of SP signaling by L-703606 (NK-R1-specific antagonist) in ovariectomized osteoporotic mice exacerbates the degeneration of bone microstructure and bone loss, with the osteoprotegerin (OPG)/RANKL ratio in the bone decreasing significantly (10). It has been demonstrated that long-term usage of SP under effective dose may not cause detrimental side effects such as osteoporosis in comparison to that of steroids, which hold promise for clinical innovation in an anti-inflammatory agent and/or stem cell mobilizer $(38,54,56)$. Prostaglandin E2 (PGE2) is known to initiate inflammation process and stimulate bone regeneration by activation prostaglandin $\mathrm{E}$ receptor 4 (EP4) receptor (50). A recent study revealed that increased PGE2 secretion by osteoblasts serves as a message molecule to transmit signals of impaired bone density to CGRP-positive sensory nerve fibers in osteoporotic animal models. PGE2 secretion tunes down sympathetic tone and rescues low bone mass upon activation of sensory nerve EP4 receptor, instead of acting directly on osteoblasts. Whether and how PGE2 precisely suppresses the activity of the sympathetic nerves at the hypothalamus level remains unclear (57).

Sensory neuropeptides in cartilage physiology and osteoarthritis $(O A)$ pathogenesis. Sensory nerve fibers have been found in the perichondrium and within the cartilage canals of rat at birth (30). It is speculated that these fibers are able to modulate the physiology and function of synovial joints and cartilage canals through trophic effects. Adult human articular chondrocytes and newborn murine costal chondrocytes endogenously produce SP and its neurokinin-1 receptor. Evidence has shown that SP significantly enhanced the expression of chondrogenesis related genes, including type I, IX, X collagen, and MMP-13 in costal chondrocytes isolated from newborn mice. It was also noted that SP stimulation increases chondrocyte proliferation rate and cell-matrix adherence in a paracrine and/or autocrine manner (31). Deletion of the SP-encoding gene Tacl in mice leads to impaired endochondral ossification, with the biomechanical feature of the non-fractured leg also differed from WT mice (8).

CGRP exerts its anabolic effect predominantly in bone and to a lesser extent in cartilage homeostasis. Dorsal root ganglion neurons which innervate growth plate cartilage could influence chondrocyte differentiation via CGRP (58). Grässel (58) speculated that upregulated levels of cAMP might act as the downstream signaling molecule that poses a negative effect on terminal chondrogenic differentiation by inhibiting matrix mineralization and delaying hypertrophy of chondrocytes. In addition, a previous study confirmed that cAMP could 
suppress alkaline phosphatase activity and type $\mathrm{X}$ collagen synthesis in chondrocytes (59). By contrast, Sang et al (43) hold the opinion that direct injection of CGRP into muscle was able to induce chondrogenic differentiation of fibro/adipogenic progenitors during neurological heterotopic ossification, a common disorder following traumatic brain injury and spinal cord injury. Since multiple intracellular signals are involved in chondrogenic differentiation, further in vitro studies are needed to understand the underlying mechanisms of sensory neuropeptides in chondrocyte regulation in different cell types.

Impaired sensory nerve innervation is considered to be associated with OA (60-62). SP- and CGRP-containing nerve fibers disappear 5 weeks after induction of OA with intra-articular injection of collagenase in a murine OA model (60). Salo et al (61) demonstrated that surgical ablation of SP- and CGRP-positive joint innervation led to OA related structural cartilage matrix damage and disease progression in rats. The synovium from OA joints exhibits massive destruction of the vascular and CGRP containing sensory fibers (62). However, it remains unknown if nerve disappearance facilitates the pathogenesis of OA or if nerves are destroyed as a consequence of OA. In addition, SP and its receptor NK-1R are involved in mechanotransduction implicated in structure preservation mechanisms. Under mechanical stimulation, gene expression of Tacl, the gene encoding SP, is upregulated in OA chondrocytes (63). Recently, a study of OA-related structural alterations in mice demonstrated the role of sensory neuropeptides in bone adaptation to acute trauma (64); loss of CGRP led to sclerosis of the subchondral bone in very early knee OA bone pathology and to general alterations of bone morphology, such as smaller medial tibia diameter. Altogether, these findings reveal the importance of sensory neurotransmitters in the process of $\mathrm{OA}$ and highlight their therapeutic potential. Neutralizing antibody to CGRP provided dose-dependent and prolonged pain reduction in rat monoiodoacetate model of OA and meniscal tear model of OA (13). However, long-term follow-up studies of structural changes are required. As abovementioned, SP may alleviate arthritis progression via its anti-inflammatory effect and regenerative potential $(15,54)$. However, dual contradictory effects may occur when SP is applied in OA, partly due to increased pain induction via the lowered pain threshold (31). SP with self-assembled peptide conjugate nanofibers that adjust the release of SP promote the recruitment of MSCs and profoundly resolve the opposing effects of SP (65). Functional role of SP during OA remains elusive, and future studies are needed to facilitate the development of novel therapies targeting the neuropeptides that are crucial for treating OA.

\section{Neuropeptides of the sympathetic nervous system (SNS)}

Tyrosine hydroxylase, a key catecholaminergic enzyme, was reported to be immunolocalized to synovia, trabecular bone and periostea $(8,16,31,66,67)$. Receptors for the neurotransmitters expressed in the SNS have also been detected in various cell types in bone tissues, including osteoclasts, osteoblasts and chondrocytes, enabling them to respond to autonomic stimuli $(19,66,68-70)$. Furthermore, some of these non-neuronal cells are also able to synthesize and secrete neurotransmitters locally, which may exert local action regardless of autonomic innervation (8,71). This section of the Review will focus on the activity of $\beta$-adrenergic receptor ( $\beta$-AR) and NPY in bone and cartilage homeostasis.

Norepinephrine (NE) and $\beta$-AR in bone metabolism. $\beta$-AR is not the only receptor mediating SNS signaling in the bone mass, as $\alpha$-adrenergic receptor ( $\alpha$-AR) isoforms also may be involved in regulating bone remodeling (70). Low NE concentrations act primarily through $\alpha$-AR on osteoblasts and osteoclasts. Activation of $\alpha_{1}$-ARs induces RANKL expression and release from osteoblasts and subsequently activates osteoclastogenesis (66). The effect of the $\beta$-AR system on bone metabolism depends on the subtype of receptors expressed on various skeletal cells (Fig. 1). $\beta_{1}$-AR predominantly exerts anabolic effect in response to mechanical stimulation; its activation increases bone formation (primarily in the periosteum) through activation of the somatotropin-insulin-like growth factor 1 (IGF-1; a growth hormone upregulated during the pubertal period) axis and inhibits bone resorption through activation of the gonadotropin-releasing hormone-gonadal axis, highlighting molecular mechanisms linking body fat and bone mass (72,73). By contrast, Khosla et al (74) studied the bone microarchitecture from 155 postmenopausal women and demonstrated that $\beta_{1}$-AR-selective blockers could improve bone microarchitecture compared with that of non- $\beta_{1}$-AR-selective blocker users. In addition, $\beta_{1}$-AR-selective blockers (atenolol, nebivolol), but not a non-selective $\beta$-AR blocker (propranolol), have favorable effects on bone turnover and bone mineral density (BMD) in postmenopausal women. The conflicting conclusion may be due to the 'low-dose spillover' effect on the $\beta_{2}$-AR, or the indirect pathway mediated through CNS $-\beta_{1}-\mathrm{AR}$ blockade.

Activation of $\beta_{2}$-ARs in bone tissue restrains bone formation and favors bone resorption (Fig. 1). Treatment of mouse bone marrow cells with the $\beta_{2}$-AR agonist isoprenaline or epinephrine promotes osteoclast formation by increasing the ratio of RANKL to OPG and the expression of pro-inflammation markers, such as IL-6 and TNF- $\alpha$ (16). $\beta_{2}$-ARs in osteoclasts participate in the bone loss induced by SNS signaling as well, with elevated intracellular ROS levels considered as the direct regulatory mechanism (19). Inhibited expression of two neurogenic markers, CGRP and NPY, was observed in osteocytic MLO-Y4 cells treated with the $\beta_{2}$-AR agonist clenbuterol, suggesting the counteractive effect of sensory nervous system and NPY in NE-induced osteoclastogenesis (69). In addition, administration of the selective $\beta_{2}$-AR antagonist butoxamine improves osteoporosis in rats associated with hyperactivity of the SNS (75); these experimental observations are consistent with those seen in clinical practices. A study in 2012 reported that plasma osteopontin levels, trabecular bone volume fraction, and trabecular thickness were inversely associated with SNS activity (measured using microneurography at the peroneal nerve) in 23 women, aged 20-72 years (76). This study revealed that a negative feedback loop mediated by osteopontin may limit the detrimental effects of SNS activity on human bone metabolism; the continuous bone loss and decreased peak bone mass led by sympathetic signaling may be age-related as post-menopausal women with osteoporosis exhibited higher sympathetic activity compared with those without osteoporosis. Such bone loss may be due to 


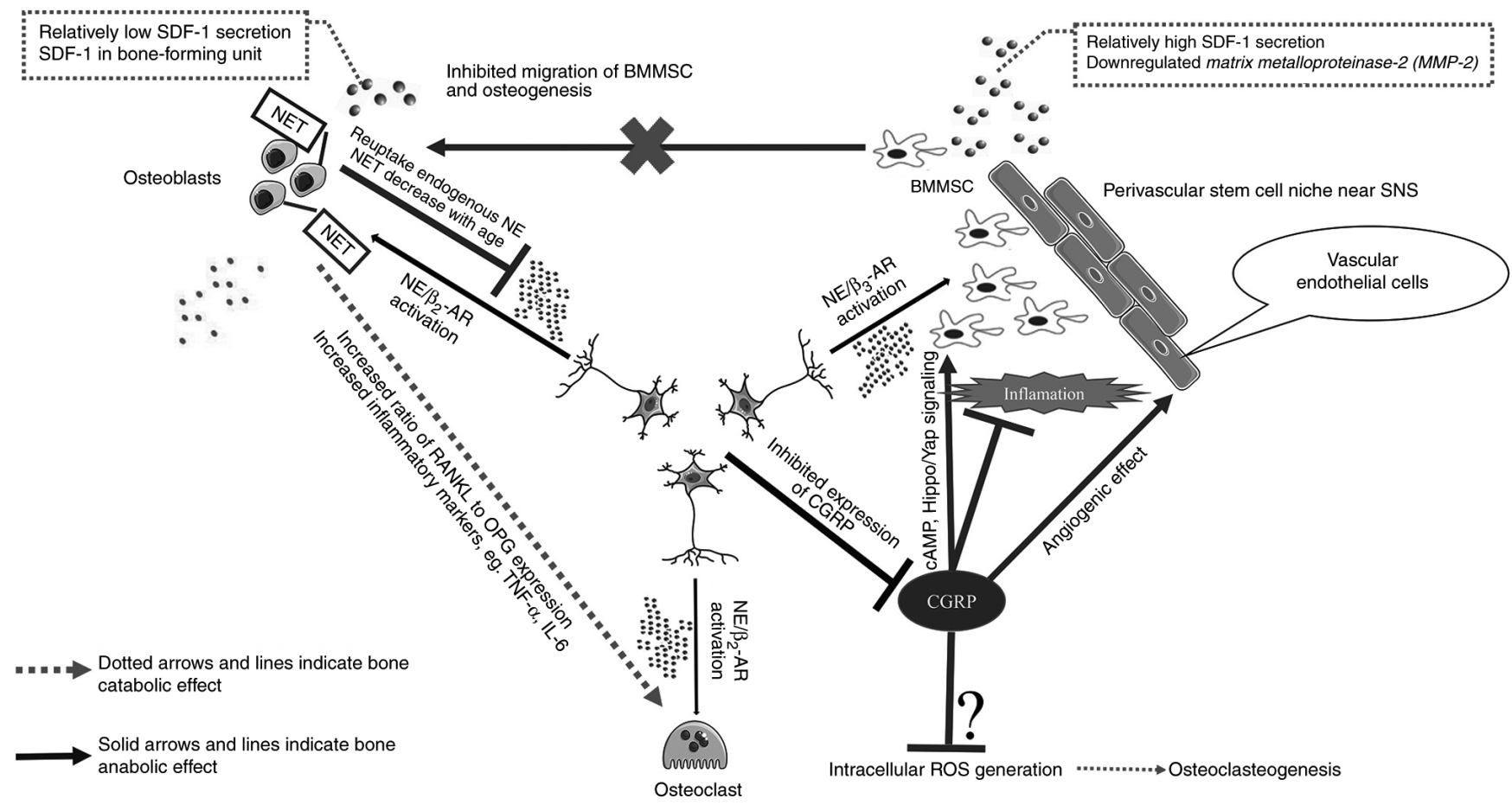

Figure 1. Schematic diagram of the sympathetic nervous system in local homeostasis of bone remodeling. Activation of $\beta_{3}$-AR increases the ratio of RANKL/OPG and pro-inflammation markers, which promotes bone resorption. $\beta_{3}$-AR may also regulate osteoclasts directly by elevating intracellular ROS levels. Expression of other neurogenic markers, such as CGRP, is inhibited upon activation of $\beta_{3}$-AR. CGRP shows osteogenic, angiogenic and anti-inflammatory effect during bone regeneration. NET expressed on osteoblasts buffers the negative effect of NE on bone as it catabolizes and replenishes NE. NET expression increases during osteoblast differentiation and decreases with age. Stimulation of $\beta_{3}$-AR not only inhibits osteogenic capacity of BMMSCs, but also restricts BMMSCs from leaving their perivascular niche by disrupting the SDF-1 concentration gradient. AR, adrenergic receptor; BMMSCs, bone marrow mesenchymal stem cells; CGRP, calcitonin gene-related peptide; IGF-1, insulin-like growth factor 1; NE, norepinephrine; NET, norepinephrine transporter; OPG, osteoprotegerin; RANKL, receptor activator of NF-кB ligand; ROS, reactive oxygen species; SDF-1, stromal cell-derived factor-1; SNS, sympathetic nervous system.

the reduction of NE clearance by NE transporter (NET) with increasing age, instead of increased sympathetic outflow. NET is a membrane pump that is expressed on differentiated osteoblast that controls presynaptic NE reuptake and helps buffer the negative effect of NE on bone (67). Ma et al (77) confirmed the expression of NET in the osteoblast lineage and the role of NET in transporting and catabolizing NE. Administration of reboxetine to block NET and the genetic deletion of Net in mice leads to compromised bone mass (77). This observation points to a complex bone regulatory system through the pre-synaptic modulation of both NE release and clearance. Such an effect in bone is opposed by parasympathetic pathways through the central IL-1-parasympathetic-bone axis which favors bone mass accrual. Nicotinic $\alpha_{2}$ and muscarinic 3 receptor subtypes exert their effect in bone remodeling; the former directly regulates osteoclasts, whereas the latter acts indirectly by inhibition of SNS (78).

$\beta_{3}$-AR expressed on bone marrow mesenchymal stem cells (BMMSCs) also influences NE mediated skeletal modulation (Fig. 1). Decreased stimulation of $\beta_{3}$-AR in BMMSCs induced by transection of cervical sympathetic trunk promotes BMMSC migration from perivascular regions to bone-forming units in a rat model of mandibular distraction osteogenesis (79). Migratory related genes (such as MMP2) and chemotaxis factor stromal cell-derived factor-1 (SDF-1) of BMMSCs were shown to be inhibited by NE in vitro. In addition, knockdown of $\beta_{3}$-AR by small interfering RNA not only preserves the osteogenic capacity of MSC, but also abolishes its migration. Sympathetic fibers work with microvascular to regulate the mobilization of hematopoietic progenitor and mesenchymal cells in long bone (80). Under distraction stress, activation of $\beta_{3}$-AR by NE restricts MSCs from leaving their perivascular niche by disrupting the SDF- 1 concentration gradient in the distraction gap $(80,81)$.

NPY in bone metabolism. NPY is a 36 amino-acid-long polypeptide whose effects are mainly mediated through signaling by receptors belonging to the $G$ protein-coupled receptor family (82). Peripheral NPY is found in the SNS where it is co-expressed with NE-mediated signaling (9). Studies have shown that NPY is negatively correlated with osteoblast activity and bone mass in mouse models with high expression levels of NPY $(22,82)$. High levels of NPY in the hypothalamus increase orexis, leading to additional weight gain and a reduction in bone mass to conserve energy. Although injection of NPY into the arcuate nucleus results in decreased bone mass, the original phenotype is not completely restored, which may be due to other peripheral roles of NPY such as those involving in the interaction between adipose tissue and energy homeostasis in a paracrine or autocrine manner (22).

At present, six NPY receptor subtypes have been identified in mammals: Y1, Y2, Y3, Y4, Y5 and Y6 (9). In the arcuate nucleus of the hypothalamus and hippocampus, NPY neurons predominantly express high levels of Y2 receptors (83), 
whereas Y1 receptors are expressed in peripheral tissues, such as osteoblasts and osteoclast lineage cells, as well as in regions of the CNS, such as the paraventricular nucleus $(84,85)$. Differentiation and proliferation of mature osteoblasts and their progenitor cells are improved in global Y1 receptor null mice (84). Oral administration of Y1 receptor antagonist led to a similar outcome (86). However, no significant difference in the phenotype of bone was observed when the Y1 receptors in the hypothalamus were knocked out, suggesting functional Y1 receptors serve an inhibitory role in the periphery (87). This result is in accordance with the findings of studies performed by Lee et al (88), in which specific knockout of $Y 1$ receptors in late and early osteoblasts led to enhanced bone mass. The underlying mechanism may involve the inhibition of the cAMP signaling pathway, followed by phosphorylation of ERK, which leads to inhibited osteoblast differentiation (18) (Fig. 2).

Denervation cultures of BMSCs from $\mathrm{Y}^{-/-}$mice have shown increased mineralization and ALP concentrations compared with the control group (89); however, no significant changes in bone mass have been identified in mice with conditional deletion of these peripheral Y2 receptors, suggesting that the Y2 receptor regulates bone remodeling mainly by reducing osteoblast function via signaling of the CNS (Fig. 2). A less significant effect was found on the activity and number of osteoclasts in a model involving complete knockout of the gene encoding the $Y 2$ receptor or conditional knockout of this gene in hypothalamic neurons (90). The simultaneous silencing of the two receptor genes did not result in an additional increase in bone mass, suggesting that the two receptors shared the same undetermined downstream pathway (87). To date, only one study describes the relationship between NPY and osteoclasts. In that study, BMM cultures from mice lacking expression of the Y6 receptor showed an increase in macrophage colony-stimulating factor/RANKL-induced osteoclastogenesis in mice (91). The NPY system also modulates angiogenic activity. NPY promotes the proliferation and migration of vascular epithelial cells and stimulates the growth of vascular smooth muscle (92). Administration of the Y2 receptor antagonist BIIE 0246 was found to reduce the capillary density of tumor tissues and serum levels of vascular endothelial growth factor (VEGF) (93); however, the mechanism is not entirely understood. Enhanced nitric oxide synthesis after NPY binding to the Y2 receptor may promote the upregulation of VEGF and angiogenesis during the process of osteogenesis (94).

SNS in cartilage physiology and OA pathogenesis. Growing evidence has highlighted the indispensable role of SNS in cartilage health. Opolka et al (31) revealed that signaling through $\beta_{2}$-ARs in murine costal chondrocytes could inhibit apoptosis and increase cell-matrix adhesion in vitro. The absence of sympathetic nerve fibers was found to profoundly delay the hypertrophy of chondrocytes and hinder the differentiation of mesenchymal callus toward a cartilaginous matrix, resulting in impaired endochondral ossification (8). Activation of $\beta_{2}$-ARs expressed on the growth plate chondrocytes prepared from embryonic E18.5 mice could stimulate proliferation and inhibit markers of chondrocyte differentiation, including Indian hedgehog and collagen type X (95). The follow-up study demonstrated that stimulation of $\beta_{2}$-AR by isoproterenol suppressed the expression of collagen type II and Sox6 through signaling of the activator protein-1 factor Jun-B (68). Signaling through $\beta_{2}$-ARs may regulate chondrogenic differentiation during embryonic endochondral ossification through interfering with the production of matrix molecules. In a rat model of temporomandibular joint OA, activation of $\beta_{2}$-AR by isoproterenol stimulates subchondral bone loss and osteoclast hyperfunction (16). Based on the aforementioned data, $\beta_{2}-\mathrm{AR}$ signal-mediated subchondral bone loss and malfunction of cartilage may be associated with the pathogenesis of OA. Previous findings suggest that $\beta$-AR blockers have antinociceptive properties $(96,97)$. A study of 873 individuals with symptomatic hip and/or knee OA and hypertension demonstrated that the use of $\beta$-AR blockers is associated with lower Western Ontario and McMaster Universities Osteoarthritis Index pain scores and lower use of opioids and other analgesics (98). Such findings may hold promise for addressing joint pain in hypertensive patients as some analgesics, especially nonsteroidal anti-inflammatory drugs, may have adverse effects on blood pressure. Given the limited space in the present Review, clinical applications of $\beta$-AR blockers on osteoporosis and joint pain are not discussed elaborately. Further studies are required for achieving a comprehensive understanding of their current clinical achievements.

NPY-secretion in chondrocytes and the presence of NPY-positive fibers in cartilage indicate that NPY may regulate the function of chondrocytes directly $(17,99)$. An in vitro study demonstrated that NPY at a concentration of $10^{-10} \mathrm{~mol} / \mathrm{l}$ significantly enhances the proliferation of murine chondrogenic cell line ATDC5 cells (17). Moreover, NPY effectively facilitates early chondrogenesis and late hypertrophy/mineralization of ATDC5 cells via Y1 receptor signaling. It seems that NPY has a positive effect on chondrocyte physiology. However, paradoxical results also exist. NPY was considered a risk factor during $\mathrm{OA}$ as its concentrations were significantly higher in the synovial fluid of OA patients compared with controls (100). Increasing synovial fluid concentrations of NPY correlated with increasing pain scores, representing a potential candidate as an OA biomarker. Overexpressed NPY was detected in human OA cartilage, partly due to various stressors such as cold exposure which results in the peripheral release of NPY from sympathetic nerves $(99,101)$. Intra-articular administration of NPY promotes chondrocyte hypertrophy and cartilage matrix degradation via the Y2 receptor, whereas Y2 receptor antagonists attenuate those responses, indicating a promising strategy for OA treatment. The underlying mechanism lies in the activation of SMAD1/5/8-SMAD4 complex in the mTORC1-dependent manner and the following upregulation of Runx 2 expression (99). Owing to the current lack of detailed knowledge about the effects of NPY on cartilage, an intense investigation is required to determine the mechanism by which SNS signaling is regulated in chondrocytes and to explore the role of this signaling in the survival of OA chondrocytes.

\section{Semaphorin $3 \mathrm{~A}$ in bone and cartilage metabolism}

Semaphorins are a family of soluble cell surface proteins that are characterized by a conserved N-terminal 'sema' domain, with their versatilities involved in large spectrum, 


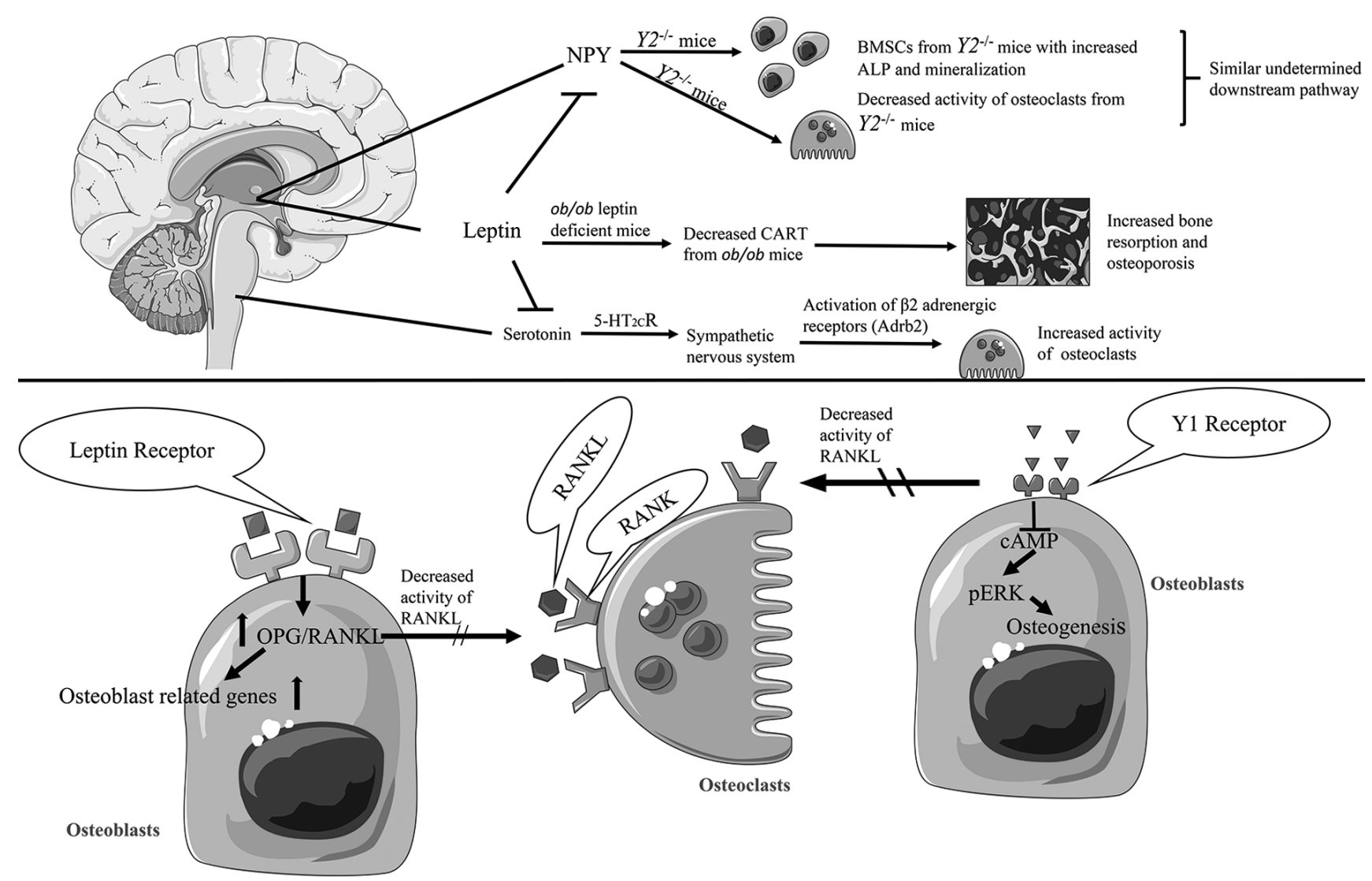

Figure 2. Schematic figure of NPY and leptin in local homeostasis of bone remodeling. NPY is widely distributed in central nervous system, with the highest distribution in the arcuate nucleus. Y1 receptors are mainly expressed in peripheral tissues such as osteoblasts and osteoclast lineage cells, and high levels of Y2 receptors are expressed in the arcuate nucleus of the hypothalamus and hippocampus. NPY from the peripheral and central nervous system is negatively correlated with osteoblast activity and bone mass. The underlying mechanism may be inhibition of the cAMP signaling pathway, followed by phosphorylation of ERK. NPY affects the activities of osteoclasts by inhibiting the response of osteoclasts to RANKL. The Y1 and Y2 NPY receptor subtypes were speculated to share the same downstream pathway, as simultaneous silencing of the two receptor genes did not result in an additional increase in bone mass. Decrease in Y1 receptor expression on the BMSCs is considered to be an important factor linking central and peripheral NPY circuits to bone. Inhibition of bone formation by leptin through central regulation at hypothalamus is the main process in bone metabolism. Leptin can reduce the action potential of serotonergic neurons in the brainstem. Serotonin binds to $5-\mathrm{HT}_{2 \mathrm{C}}$ receptors expressed on neurons in the ventromedial hypothalamus to regulate bone mass. Leptin acts on the hypothalamus to inhibit the expression of NPY, which subsequently leads to enhanced bone anabolism. Decreased CART expression was reported in the hypothalamus of $o b / o b$ obese leptin-deficient mice, which induces osteoporosis and an increase in bone resorption. Leptin can also activate its receptors in osteoblasts and osteoclasts to inhibit bone resorption and promote bone formation, partly through increasing the amount of osteoprotectin and reducing the secretion of RANKL. 5- $\mathrm{HT}_{2 \mathrm{C}} \mathrm{R}$, 5-hydroxytryptamine $2 \mathrm{C}$ receptor; BMSCs, bone marrow stromal cells; CART, cocaine- and amphetamine-regulated transcript; NPY, Neuropeptide Y; OPG, osteoprotegerin; pERK, phosphorylated ERK; RANKL, receptor activator of NF-кB ligand.

such as cell differentiation, angiogenesis and immunological responses (102). Among the subclasses of semaphorins, Sema3A shows a higher expression in the mouse calvaria compared with other semaphorins and serves as a chemorepellent or chemoattractant ligand for repulsive growth cone guidance in the development of the central nervous system $(20,21,103)$. Sema3A has dual effects on both osteoblasts and osteoclasts, with its expression levels decreased during osteoclast differentiation and increased during osteoblast differentiation $(20,104)$. An in vitro study of conditioned medium from osteoprotegerin (OPG)-deficient mice reveals that suppression of immunoreceptor tyrosine-based activation motif and RhoA signaling pathways upon activation of neuropilin-1 (Nrp1), a Sema3A receptor, leads to inhibited osteoclast differentiation (105). Additionally, Sema3A stimulates bone formation via $\mathrm{Wnt} / \beta$-catenin signaling in an autocrine fashion, which is mediated by the effector of the intrinsic GTPase Rac1 through FERM, RhoGEF and pleckstrin domain protein 2 activity (a FERM domain-containing guanine nucleotide exchange factor) at the cytoplasmic domain of plexins expressed on osteoblasts $(20,105)$. Sema3A also suppresses bone resorption by competing with the receptor complex composed of the DNAX-activating protein of $12 \mathrm{kDa}$ and triggering receptors expressed on myeloid cell 2 in osteoclasts, simultaneously (106). Local injection of Sema3A exerts osteoprotective effects in a rat model of osteoporosis (104). Accordingly, Sema $3 A^{-/}$mice exhibit decreased bone formation. However, lower bone mass was not observed in osteoblast-specific Sema3A-deficient mice (Sema3A coll $^{-1-}$ and Sema $3 A a_{o s x}{ }^{-1-}$ mice). Fukuda et al (20) demonstrated that the bone mass and the number of sensory innervations of trabecular bone (including CGRP- and TRPV1-positive fibers) were significantly reduced in mice lacking neuron-derived Sema3A (Sema3A $A_{\text {synapsin }}{ }^{-1-}$ mice), whereas sympathetic innervations were unchanged. Collectively, these studies suggest a positive role of Sema3A in regulating bone turnover, by directly acting on osteoblasts or by indirectly modulating sensory nerve projection into bone. 
Gomez et al (103) reported that Sema3A and Plexin A2 mRNA were expressed in the MC615 mouse chondrogenic cell line before the onset of neurovascular invasion during endochondral ossification. In OA cartilage, Sema3 A and its receptor Nrp1 were found to be upregulated $(21,107)$. Okubo et al (21) first described that Sema3A functions competitively or cooperatively with VEGF-165 in modulating chondrocyte cloning by binding to the common receptor Nrp-1. Sema3A antagonized certain effects induced by VEGF signaling, including chondrocyte migration, overexpression of MMPs and phosphorylation of ERK and focal adhesion kinase in chondrocytes (21). It seems that temporospatial regulation of Sema3A expression could contribute to the appropriate mobilization of lesional chondrocytes and chondrocyte cloning, a sign of active repair of damaged cartilage in OA. However, Sun et al (107) revealed the detrimental effect of Sema3A in OA. In that study, the proapoptotic function of augmented Sema3A signaling through impairing PI3K/Akt prosurvival signaling was identified in OA chondrocytes, along with subsequent transcriptional activation orchestrated by CCAAT-enhancer-binding protein $\beta$. Although the results of these studies are inconsistent, it is certain that, as a sensory and sympathetic nerve-specific axon guidance molecule or repellent factor, Sema3A may direct the growing nerve fibers to the target skeletal tissue through repulsive guidance. Consistent with the study performed by Okubo et al (21), Gomez et al (103) revealed that Sema3A could inhibit neurovascularization of the cartilage during skeletal development. Impaired sensory and sympathetic nerve innervation, as well as impaired vascularization were found to be associated with OA (60-62). In light of the observations discussed above, it could be hypothesized that Sema3A may interact with other local neural signaling during OA chondrocyte survival. Further research is needed to establish a comprehensive understanding and a definite role for Sema3A in OA cartilage.

\section{Comprehensive description of leptin in bone and cartilage metabolism}

Retrograde trans-synaptic tracing has revealed a link between neural tracts from the femoral bone marrow and the CNS (108). The CNS controls skeletal homeostasis by altering the secretion of endocrine factors, such as leptin, and affecting efferent neural outflow of circulating molecules (109). This section is a comprehensive description of leptin.

Leptin in bone metabolism. Leptin is a pleiotropic adipokine that functions in energy control in various types of cells (110). It is widely accepted that increased leptin expression results in decreased bone mass through regulating the sympathetic outflow from the hypothalamus, with neural signals in turn activating $\beta_{2}$-AR expressed on osteoblasts $(109,111)$. However, opposite conclusions from other studies indicate multiple regulatory effects of leptin (Fig. 2). For example, decreased cocaine- and amphetamine-regulated transcript expression was found in the hypothalamus of leptin-deficient $o b / o b$ obese mice, which induced osteoporosis and an increase in bone resorption peripherally through RANKL (112). Leptin can also modulate bone mass by reducing the action potential of brain serotonergic neurons and tryptophan hydroxylase 2 expression.
Serotonin binds to 5-hydroxytryptamine $(5-\mathrm{HT})_{2 \mathrm{C}}$ receptors expressed on neurons in the ventromedial hypothalamus to regulate bone mass (113). The leptin receptor is co-expressed with NPY-positive neurons in the arcuate nucleus of the hypothalamus in mice (114). Previous studies have demonstrated that $\mathrm{Y} 2$ receptor deletion results in no additional osteogenic stimulating effect in the absence of leptin. By contrast, Y2 receptor deletion can double the activity of osteoblasts in the presence of leptin, suggesting a leptin-dependent, Y2 receptor-mediated bone metabolic pathway $(23,115)$ (Fig. 2). Decreased leptin levels or leptin resistance could potentially inhibit cortical bone formation by NPY signaling from the central nervous system (24).

Although in the central nervous system, leptin levels have a negative impact on bone, leptin originating from the PNS is considered anabolic to bone (Fig. 2). Peripheral effects of leptin with enhanced expression of pro-osteogenic factors and decreased bone resorption by modulating OPG/RANKL signaling have been observed (116). Turner et al (117) reported an increased perimeter of osteoblast-lined bone in $o b / o b$ mice. The stimulatory effect of leptin on bone may be region-specific. Earlier observations showed that $o b / o b$ leptin-deficient mice exhibited significantly increased lumbar BMD, lumbar bone mineral content (BMC) and vertebral length, but lower limb BMD, lower limb BMC and shorter femoral length (118). A study of leptin-deficient adolescent mice revealed similar results; leptin-deficiency could decrease the deposition of mineral and matrix in femurs, but not in lumbar vertebrae (119).

Leptin in cartilage physiology and OA pathogenesis. Previous studies have identified the expression of leptin and its specific receptor in joint cells, including synovium, osteophytes, chondrocytes and bone cells $(120,121)$. Following leptin treatment, elevated levels of TGF- $\beta$ and IGF-1, as well as increased synthesis of cartilage proteoglycan, were observed in articular cartilage cells (121). A study of primary chondrocyte cultures from mice vertebral growth plate (VGP) and tibial growth plate (TGP) suggested a region-specific effect of leptin on the chondrogenesis of the growth plate; a stimulatory effect on the proliferation and differentiation of TGP chondrocytes, but an inhibitory effect on the VGP chondrocytes was observed (120). These results are consistent with a previous observation that the effects of leptin differ significantly between axial and appendicular regions of bones, with shorter femora and tibias but with longer vertebral lengths, as well as the disturbed two-dimensional columnar structure of tibial growth plate chondrocytes in $o b / o b$ mice, compared with the WT mice (118). Further characterization of leptin regarding its differential regulation in TGP and in VGP may give useful hints for explaining its mode of action in cartilage homeostasis.

In addition to the role of leptin in osteogenesis and chondrogenesis, accumulating data have suggested an initiative role of leptin in OA development. Obesity was found to be a risk factor for digital OA involving non-weight-bearing joints (122). Clinical evidence demonstrates that leptin levels in serum and synovial fluid are associated with OA progression (121). Leptin could induce mRNA expression of matrix-degrading enzymes MMP1, MMP13 and ADAMTS4 in chondrocytes, and thus stimulates OA development. Increased BMP2 expression through histone deacetylase $3 / 4$ was identified as the 
underlying mechanism $(123,124)$. These findings indicate a potential damage-promoting role of the BMP2 autocrine effect in human chondrocytes under leptin-induced OA pathogenesis. Although a previous study performed by the same research team suggested the BMP2 autocrine effect had a reparative role in leptin-stimulated OA chondrocytes by increasing the anabolic collagen II expression, the authors suggested a role of the BMP2 autocrine effect of leptin induction as a reparative and rescue mechanism (125). They hypothesized that the BMP2 autocrine effect of leptin induction in cartilage removes the damaged tissues, providing space for the newly synthesized matrix protein $(124,125)$. Based on these data, investigation of chondrogenic progenitor cells (CPCs) further revealed that altered differentiation fate of CPCs is another important mechanism mediating leptin-induced cartilage degeneration. High doses of leptin increased osteogenic potential of CPCs but decreased their migratory ability and inhibited their chondrogenic potential, leading to disequilibrium in cartilage tissue homeostasis and cartilage degeneration over time. Cell cycle arrest and senescence via activation of the p53/p21 pathway and inhibiting the Sirt1 pathway were also induced by leptin in CPCs. The conclusions from these in vitro studies were supported by the results from patients with knee OA with activated leptin pathway (126).

Leptin is involved in appetite control, energy consumption and various inflammatory processes, such as OA and nociception (121). It appears that elevated leptin levels, due to increased body fat percentage and aging, are detrimental to cartilage homeostasis (122). Further studies are required to elucidate whether the higher levels of leptin observed in severe $\mathrm{OA}$ are associated with biomechanical forces. The potential immunological function of leptin in the interaction between fat and bone will require further study.

\section{Schwann cells and neurotrophic factors in bone metabolism}

Neuroglial cells serve indispensable roles during neural migration and differentiation $(25,26,127,128)$. Given the well-known properties of glial cell (such as Schwann cell) graft in promoting sensory responses of osseointegrated implants, as well as the expression of neuroglial markers detected in MSCs in the absence of any kind of differentiation stimuli, it is important to discuss the interactions between bone and neuroglial cells and to discuss the molecules involved (128).

Schwann cells, the glial cells that surround the myelinated nerves in the PNS, have been reported to participate in peripheral tissue regeneration, such as skin or mammalian digit tip $(25,129)$. Osteoblasts co-cultured with Schwann cells derived from the rat sciatic nerves exhibit an increase in proliferation and an elevated number of calcified nodules (27). It was also noted that conditioned medium collected from YST-1 Schwann cells facilitated bone regeneration in wounded periodontal tissue, probably through the ERK signaling pathway. A study of denervation-mediated Schwann cell paucity of inferior alveolar nerve revealed that the function of mouse skeletal stem cells during mandibular healing was dependent upon paracrine growth factors from Schwann cells, including platelet-derived growth factor-AA and oncostatin M (26). A previous study conducted by Johnston et al (25) demonstrated that these factors, along with Schwann cell transcriptional reprogramming, are involved in the regenerative capacity of the digit tip.

Brain-derived neurotrophic factor (BDNF), neurotrophin-3 (NT-3) and nerve growth factor (NGF) are major signaling molecules secreted by Schwann cells that make important contributions to the proliferation, differentiation and repair of neurons and glial cells in a temporospatial manner $(27,127)$. The mRNA levels of BDNF and NGF in Schwann cells are significantly elevated when co-cultured with osteoblasts, suggesting the positive effects of Schwann cells on osseointegration during regeneration of nerve endings (27). In fact, these particular neurotrophins have been confirmed to serve a crucial role in the regeneration of non-neural tissues, including vessel formation and osteogenic process, probably through recruitment and activation of specific transmembrane tyrosine kinase receptor (trk), trkA, trkB and trkC (the receptors of NGF, BDNF and NT-3, respectively) on certain non-neural cells, including bone marrow stromal cells, osteoblasts and endothelial cells (127,130-132). Besides osteogenesis, NGF also participates in the physiological and pathophysiological conditions of cartilage. NGF-positive chondrocytes in articular cartilage of OA samples are co-localized with nociceptive CGRP-immunoreactive nerve fibers in the same vascular channels, indicating increased NGF production may contribute to OA pain (133). BDNF is less studied than NGF, but also serves pivotal roles and has been detected in various tissues or cell types, such as bone, cartilage, fracture callus, osteoblasts and vascular endothelial cells (127,130-132,134). In the process of fracture repair, both BDNF and trkB were expressed during the processes of new vessel formation (131). A recent study demonstrated that BDNF could induce angiogenesis by controlling the expression and secretion of VEGF from osteoblasts (130). Treating BMSCs with $100 \mathrm{ng} / \mathrm{ml} \mathrm{BDNF}$ was found to elicit the most effective response in mineralized nodule formation and ALP activity (127). Activation of the trkB/ERK1/2 signaling cascade was identified as the next step downstream, which promotes the expression of the angiogenesis-related gene VEGF and upregulates osteoblastic transcription factors, such as Runx2 and Osterix $(127,130)$. Consistent with the study performed by Foudah et al (128), neurogenic biomarkers, including microtubule-associated protein 2, glial fibrillary acidic protein, neural/glial antigen 2 and $\beta$-tubulin III, are also highly expressed in MSCs during in vitro osteogenic differentiation under the treatment of BDNF, indicating that neuralization may act simultaneously and in a complicated manner with effective bone repairing in newly formed tissues $(127,128)$. Compared with peripherally active BDNF, BDNF from the central neural system has the opposite effect on bone. Central BDNF deletion produces a positive impact on bone, along with metabolic actions including hyperphagia, obesity and increased abdominal white adipose tissue (111). Such phenotype is similar to that of the high bone mass leptin-deficient $o b / o b$ mouse (24). It is hypothesized that BDNF may have dual beneficial effects of reversing low bone mass and obesity through a direct effect on osteoblasts in bone, and crossing the blood-brain barrier to act centrally on the hypothalamus $(109,111)$.

NT-3 has been shown to promote osteogenesis by increasing BMP2-mediated Smad activation in BMSCs, 


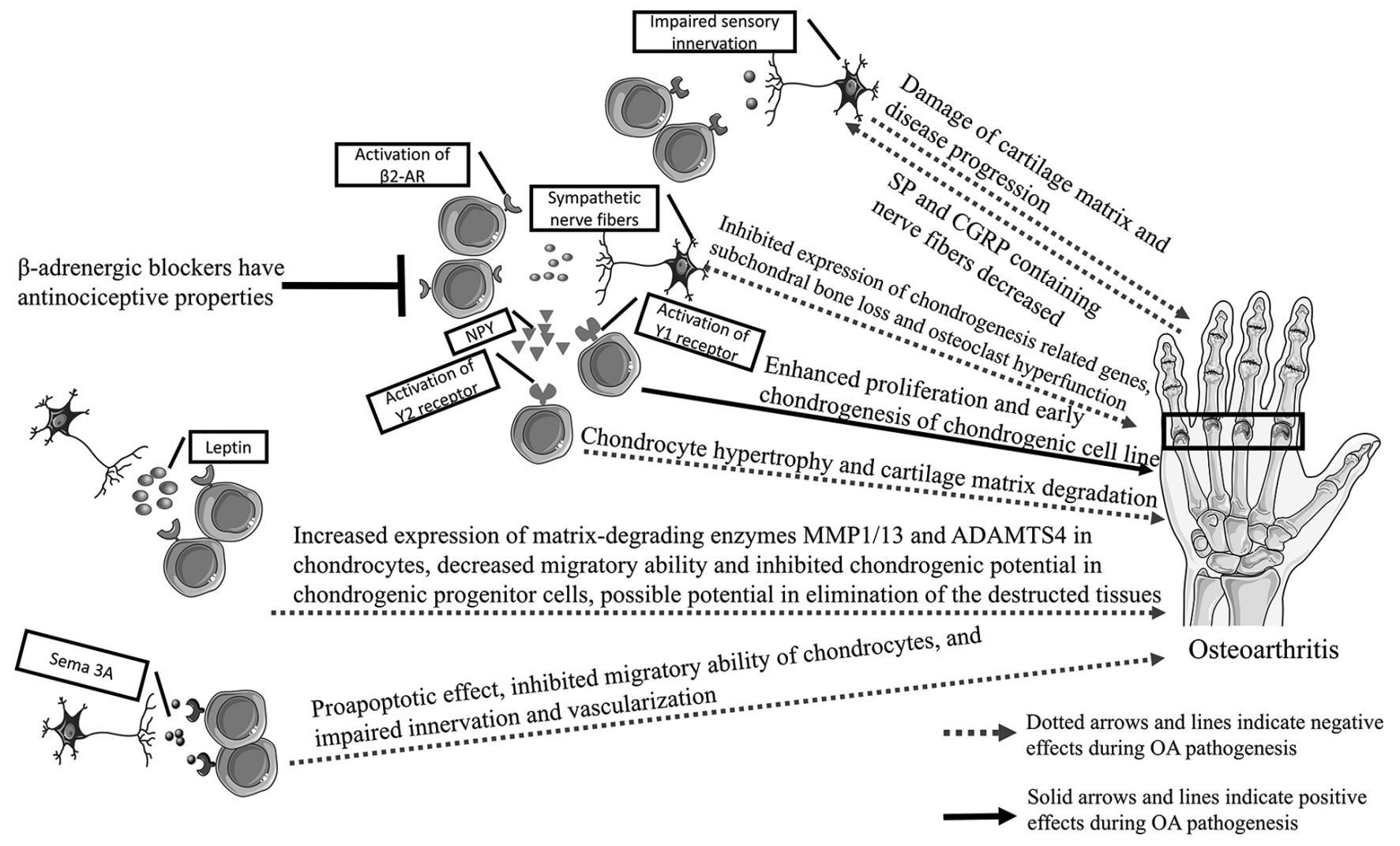

Figure 3. Various neuropeptides in OA pathogenesis. Sensory neuropeptide SP and CGRP exert trophic effects on cartilage cells. Impaired sensory nerve innervation is considered to be associated with OA. Activation of $\beta_{2}$-ARs expressed on the growth plate chondrocytes inhibits expression of chondrogenesis related genes, interferes with the production of matrix molecules and leads to malfunction of cartilage. NPY exerts a protective effect through Y1 receptor, whereas it exacerbates OA progress via Y2 signaling. Leptin induces mRNA expression of matrix-degrading enzymes in chondrocytes, inhibits the migration ability and chondrogenic potential of chondrogenic progenitor cells. Sema3A antagonizes chondrocyte migration induced by VEGF signaling. Augmented Sema3A signaling induces proapoptotic effect in chondrocytes. During OA pathogenesis, Sema3A inhibits neuro-vascularization of the cartilage, resulting in impaired sensory and sympathetic nerve innervation, and impaired vascularization. AR, adrenergic receptor; CGRP, calcitonin gene-related peptide; OA, osteoarthritis; SP, substance P.

while it inhibits collagen II expression and suppress chondrogenesis (132). However, NT-3 accelerates chondrogenesis of mesenchymal stem-like cells acquired from the endothelial progenitor cells underwent endothelial-mesenchymal transition, which serves an important role during heterotopic ossification (135). Similar to BDNF, NT-3 also promotes VEGF secretion of BMSCs and endothelial cells, partially through the PI3K/Akt signaling pathway; the enhanced vascularization effect accelerates diabetic wound healing and promotes bony repair at the injured growth plate $(132,136)$. NT-3 could promote axonal growth and stimulate the subsequent secretion of various trophic molecules from new nerve fibers; these trophic molecules may activate vascularization by releasing factors such as NGF and SP (27,137). Thus, an intricate interaction among different types of neurotrophins through the paracrine system, probably acting in a positive feedback loop, is speculated to be involved in tissue regeneration. Although ERK1/2 and PI3K/Akt activation were known to serve essential roles in osteogenesis under the treatment of these neurotrophins, further studies are still needed to investigate whether the Akt and ERK1/2 activated pathways have direct or indirect effect enacting bone healing.

Glial cell line-derived neurotrophic factor (GDNF), a member of the TGF- $\beta$ superfamily, is another important bioactive molecule involved in bone cell proliferation and differentiation $(138,139)$. The nuclear transcription factor murine GDNF inducible factor (mGIF) is homologous to the human TGF- $\beta$ inducible early gene (TIEG) (139). TIEG is suggested to be associated with osteoblast differentiation and osteo-protective effect as it is crucial for the expression of Osterix induced by bone-related cytokines such as TGF- $\beta$ and BMP2 in osteoblast cells $(140,141)$. Further studies are required to investigate whether $\mathrm{mGIF}$ shares a similar role as TIEG in bone metabolism. In a study of rat wounded periodontal tissues, elevated expression of GDNF promoted the migration of Schwann cells and helped induce alveolar bone regeneration (138). Gale et al (142) demonstrated that recombinant GDNF dose-dependently promoted MC3T3-E1 cell proliferation in serum-free conditions, whereas ALP activity was inversely related to mitotic activity. In addition, high concentrations of GDNF could inhibit osteoblast growth in serum-supplemented culture medium, with a slight increase in ALP activity. The mechanisms and physiological implications underlying these findings have not been elucidated, but may be due to a novel role in bone metabolism mediated by functional signaling through the GDNF family receptor, GFRa1, and the tyrosine kinase transmembrane co-receptor RET expressed on osteoblasts (142). 


\section{Summary}

Neural regulatory mechanisms correlate with the activity of other homeostatic networks and represent more intricate and synergistic interactions than previously imagined. Various resident cell types of the musculoskeletal system, including mesenchymal stem cells, synovial fibroblasts, bone cells and chondrocytes, express receptors for different neurotransmitters and respond to certain neuronal stimuli $(17,18,20,99,1$ $20,132,142)$. This Review focused on a precise orchestration of cytokines, protein and gene expression levels and cell signal transduction pathways. The autonomic nervous system regulates bone mass and the function of skeletal cells via connecting the central control (such as the sympathetic outflow from the hypothalamic neurons) and terminal receptors expressed on bone cells, and the innervation of sensory nerves subsequently nourishes the bones by secreting different neuropeptides $(11,22,33,40,47,77,78,81)$. Some neuropeptides may exert totally opposite effects due to different concentrations and various receptor-ligand interaction in different tissue $(33,35,41,118)$. A similar complexity for neuronal regulation of skeletal cell differentiation and function is observed for certain neurotransmitters (such as leptin and NPY) mediated through the activation of central receptors different from those in peripheral nerves $(23,91,113,117)$. These neuronal signals also regulate physiological and pathological conditions of cartilage by affecting chondrocyte proliferation, secretion, adhesion and terminal differentiation $(21,95,99,107,124)$ (Fig. 3). Healthy cartilage has long been considered an inert tissue as it contains no blood vessels or lymphatics and is not innervated by nerve fibers (58). However, alterations in innervation and abnormal levels of certain neuropeptides are considered to be partly accountable for degenerative alterations in joint tissues such as osteoarthritis $(61,62,100,121,122)$. The effects of agonists or antagonists of certain receptors in normal physiological and pathological states provide useful insights for exploring the mechanisms of action of drugs and developing novel strategies for treating skeletal disorders $(13,65,98)$.

The maintenance of proper bone homeostasis under neuronal control has gathered much interest, but remains an area of substantial controversy. The balance of the central and peripheral neural effects on skeleton might vary according to baseline circulating levels of the related bioactive molecules, presence of specific pathologies and different species. The neuropeptides along with their receptors discussed in this paper are not the only factors that serve a regulatory role on the skeleton. Additional experimental studies are required to focus on other local and systemic effectors, such as mechanical loading, endocrine hormones and immune microenvironment, that influence neuromodulation of musculoskeletal physiologies and pathophysiologies. Neural inputs that link skeleton to CNS, such as the hypothalamus, are also vital in modulating energy availability across the entire body. Notably, a significant amount of energy is utilized during the maintenance of skeletal functioning and behavior. However, it is currently not well understood and or thoroughly discussed in the literature how changes in the nutrient and energy profile (such as obesity and anorexia) affect skeletal homeostasis. Owing to the current limited understanding of innervation pattern of subchondral bone and cartilage observed in OA, a clearer insight into actual pathological neuronal-skeletal interactions in OA will require additional discussions. To date, there are major limitations regarding the clinical evidence about the application of certain neurotransmitters as well as the antagonists or agonists of their receptors in skeletal disorders, further studies are required to determine their role as effective therapeutic agents or the targets of manual intervention. Taken together, study of these neuropeptides provides a basis for translational research of systemic bone and cartilage metabolism and opens up new avenues for the development of novel strategies to combat skeletal diseases of various pathological etiologies.

\section{Acknowledgements}

Not applicable.

\section{Funding}

This work was supported by the National Natural Science Foundation of China (grant nos. NSFC 81572121 and 81802156).

\section{Availability of data and materials}

Not applicable.

\section{Authors' contributions}

XW drafted the manuscript. XW and JX conceived and designed the framework of this article. JX and QK collected and analyzed the literature. All authors read and approved the final manuscript.

\section{Ethics approval and consent to participate}

Not applicable.

\section{Patient consent for publication}

Not applicable.

\section{Competing interests}

The authors declare that they have no competing interests.

\section{References}

1. Florencio-Silva R, Sasso GR, Sasso-Cerri E, Simões MJ and Cerri PS: Biology of bone tissue: Structure, function, and factors that influence bone cells. Biomed Res Int 2015: 421746, 2015.

2. Mertens C, Decker C, Engel M, Sander A, Hoffmann J and Freier K: Early bone resorption of free microvascular reanastomized bone grafts for mandibular reconstruction-a comparison of iliac crest and fibula grafts. J Craniomaxillofac Surg 42: e217-e223, 2014.

3. Fan JJ, Mu TW, Qin JJ, Bi L and Pei GX: Different effects of implanting sensory nerve or blood vessel on the vascularization, neurotization, and osteogenesis of tissue-engineered bone in vivo. Biomed Res Int 2014: 412570, 2014.

4. Wang L, Wei JH, Yang X, Yang ZH, Sun MY, Cheng XB, Xu LQ, Lei DL and Zhang CP: Preventing early-stage graft bone resorption by simultaneous innervation: Innervated iliac bone flap for mandibular reconstruction. Plast Reconstr Surg 139: e1152-e1161, 2017. 
5. Brady RD, Grills BL, Church JE, Walsh NC, McDonald AC, Agoston DV, Sun M, O'Brien TJ, Shultz SR and McDonald SJ: Closed head experimental traumatic brain injury increases size and bone volume of callus in mice with concomitant tibial fracture. Sci Rep 6: 34491, 2016.

6. Martin CD, Jimenez-Andrade JM, Ghilardi JR and Mantyh PW: Organization of a unique net-like meshwork of CGRP+ sensory fibers in the mouse periosteum: Implications for the generation and maintenance of bone fracture pain. Neurosci Lett 427: 148-152, 2007.

7. Matsuo K, Ji S, Miya A, Yoda M, Hamada Y, Tanaka T, Takao-Kawabata R, Kawaai K, Kuroda Y and Shibata S: Innervation of the tibial epiphysis through the intercondylar foramen. Bone 120: 297-304, 2019.

8. Niedermair T, Kuhn V, Doranehgard F, Stange R, Wieskötter B, Beckmann J, Salmen P, Springorum HR, Straub RH, Zimmer A, et al: Absence of substance $\mathrm{P}$ and the sympathetic nervous system impact on bone structure and chondrocyte differentiation in an adult model of endochondral ossification. Matrix Biol 38: 22-35, 2014

9. Horsnell $\mathrm{H}$ and Baldock PA: Osteoblastic actions of the neuropeptide Y system to regulate bone and energy homeostasis. Curr Osteop Rep 14: 26-31, 2016.

10. Zheng XF, Zhao ED, He JY, Zhang YH, Jiang SD and Jiang LS: Inhibition of substance $\mathrm{P}$ signaling aggravates the bone loss in ovariectomy-induced osteoporosis. Prog Biophys Mol Biol 122: $112-121,2016$

11. Wang T, Guo Y, Yuan Y, Xin N, Zhang Q, Guo Q and Gong P. Deficiency of $\alpha$ Calcitonin-gene-related peptide impairs peri-implant angiogenesis and osseointegration via suppressive vasodilative activity. Biochem Biophys Res Commun 498: 139-145, 2018.

12. Fu S, Mei G, Wang Z, Zou ZL, Liu S, Pei GX, Bi L and Jin D Neuropeptide substance $\mathrm{P}$ improves osteoblastic and angiogenic differentiation capacity of bone marrow stem cells in vitro. Biomed Res Int 2014: 596023, 2014

13. Benschop RJ, Collins EC, Darling RJ, Allan BW, Leung D, Conner EM, Nelson J, Gaynor B, Xu J, Wang XF, et al: Development of a novel antibody to calcitonin gene-related peptide for the treatment of osteoarthritis-related pain. Osteoarthritis Cartilage 22: 578-585, 2014.

14. Duan JX, Zhou Y, Zhou AY, Guan XX, Liu T, Yang HH, Xie H and Chen P: Calcitonin gene-related peptide exerts anti-inflammatory property through regulating murine macrophages polarization in vitro. Mol Immunol 91: 105-113, 2017.

15. Lim JE, Chung E and Son Y: A neuropeptide, Substance-P, directly induces tissue-repairing M2 like macrophages by activating the $\mathrm{PI} 3 \mathrm{~K} / \mathrm{Akt} / \mathrm{mTOR}$ pathway even in the presence of IFN $\gamma$. Sci Rep 7: 9417, 2017.

16. Jiao K, Niu LN, Li QH, Ren GT, Zhao CM, Liu YD, Tay FR and Wang MQ: $\beta 2$-Adrenergic signal transduction plays a detrimental role in subchondral bone loss of temporomandibular joint in osteoarthritis. Sci Rep 5: 12593, 2015.

17. Chen R, Hao Z, Chen X, Fu Q and Ma Y: Neuropeptide $Y$ enhances proliferation and chondrogenic differentiation of ATDC5 cells. Neuropeptides 80: 102022, 2020.

18. Yu W, Zhu C, Xu W, Jiang L and Jiang S: Neuropeptide Y1 receptor regulates glucocorticoid-induced inhibition of osteoblast differentiation in murine MC3T3-E1 cells via ERK signaling. Int J Mol Sci 17: 2150, 2016.

19. Kondo H, Takeuchi S and Togari A: $\beta$-Adrenergic signaling stimulates osteoclastogenesis via reactive oxygen species. Am J Physiol Endocrinol Metab 304: E507-E515, 2013.

20. Fukuda T, Takeda S, Xu R, Ochi H, Sunamura S, Sato T, Shibata S, Yoshida Y, Gu Z, Kimura A, et al: Sema3A regulates bone-mass accrual through sensory innervations. Nature 497 490-493, 2013

21. Okubo M, Kimura T, Fujita Y, Mochizuki S, Niki Y, Enomoto H, Suda Y, Toyama Y and Okada Y: Semaphorin 3A is expressed in human osteoarthritic cartilage and antagonizes vascular endothelial growth factor 165-promoted chondrocyte migration: An implication for chondrocyte cloning. Arthritis Rheum 63: 3000-3009, 2011.

22. Baldock PA, Lee NJ, Driessler F, Lin S, Allison S, Stehrer B, Lin EJ, Zhang L, Enriquez RF, Wong IP, et al: Neuropeptide Y knockout mice reveal a central role of NPY in the coordination of bone mass to body weight. PLoS One 4: e8415, 2009.

23. Baldock PA, Allison S, McDonald MM, Sainsbury A, Enriquez RF, Little DG, Eisman JA, Gardiner EM and Herzog H: Hypothalamic regulation of cortical bone mass: Opposing activity of Y2 receptor and leptin pathways. J Bone Miner Res 21: 1600-1607, 2006.
24. Wong IP, Nguyen AD, Khor EC, Enriquez RF, Eisman JA, Sainsbury A, Herzog H and Baldock PA: Neuropeptide Y is a critical modulator of leptin's regulation of cortical bone. J Bone Miner Res 28: 886-898, 2013.

25. Johnston AP, Yuzwa SA, Carr MJ, Mahmud N, Storer MA, Krause MP, Jones K, Paul S, Kaplan DR and Miller FD: Dedifferentiated schwann cell precursors Secreting paracrine factors are required for regeneration of the mammalian digit tip. Cell Stem Cell 19: 433-448, 2016.

26. Jones RE, Salhotra A, Robertson KS, Ransom RC, Foster DS, Shah HN, Quarto N, Wan DC and Longaker MT: Skeletal stem cell-schwann cell circuitry in mandibular repair. Cell Rep 28: 2757-2766.e5, 2019.

27. Cai XX, Luo E and Yuan Q: Interaction between Schwann cells and osteoblasts in vitro. Int J Oral Sci 2: 74-81, 2010.

28. Castañeda-Corral G, Jimenez-Andrade JM, Bloom AP, Taylor RN, Mantyh WG, Kaczmarska MJ, Ghilardi JR and Mantyh PW: The majority of myelinated and unmyelinated sensory nerve fibers that innervate bone express the tropomyosin receptor kinase A. Neuroscience 178: 196-207, 2011.

29. Wu ZX, Barker JS, Batchelor TP and Dey RD: Interleukin (IL)-1 regulates ozone-enhanced tracheal smooth muscle responsiveness by increasing substance $\mathrm{P}(\mathrm{SP})$ production in intrinsic airway neurons of ferret. Respir Physiol Neurobiol 164: 300-311, 2008.

30. Li FX, Xu F, Lin X, Wu F, Zhong JY, Wang Y, Guo B, Zheng MH, Shan SK and Yuan LQ: The role of substance $P$ in the regulation of bone and cartilage metabolic activity. Front Endocrinol (Lausanne) 11: 77, 2020

31. Opolka A, Straub RH, Pasoldt A, Grifka J and Grässel S: Substance $\mathrm{P}$ and norepinephrine modulate murine chondrocyte proliferation and apoptosis. Arthritis Rheum 64: 729-739, 2012.

32. Oliva F, Tarantino U and Maffulli N: Immunohistochemical localization of calcitonin gene-related peptide and substance $\mathrm{P}$ in the rat knee cartilage at birth. Physiol Res 54: 549-556, 2005.

33. Wang L, Zhao R, Shi X, Wei T, Halloran BP, Clark DJ, Jacobs CR and Kingery WS: Substance P stimulates bone marrow stromal cell osteogenic activity, osteoclast differentiation, and resorption activity in vitro. Bone 45: 309-320, 2009.

34. Mei G, Zou Z, Fu S, Xia L, Zhou J, Zhang Y, Tuo Y, Wang Z and Jin D: Substance P activates the Wnt signal transduction pathway and enhances the differentiation of mouse preosteoblastic MC3T3-E1 cells. Int J Mol Sci 15: 6224-6240, 2014.

35. Tuzmen C and Campbell PG: Crosstalk between neuropeptides SP and CGRP in regulation of BMP2-induced bone differentiation. Connect Tissue Res 59 (Supp1): S81-S90, 2018.

36. Matsui S, Yamane T, Kobayashi-Hattori K and Oishi Y: Calcitonin gene-related peptide regulates mitogen-activated protein kinase pathway to decrease transforming growth factor $\beta 1$-induced hepatic plasminogen activator inhibitor-1 mRNA expression in HepG2 cells. Biosci Biotechnol Biochem78: 787-790, 2014.

37. Goto T, Nakao K, Gunjigake KK, Kido MA, Kobayashi S and Tanaka T: Substance P stimulates late-stage rat osteoblastic bone formation through neurokinin-1 receptors. Neuropeptides 41: 25-31, 2007

38. Hong HS, Lee J, Lee E, Kwon YS, Lee E, Ahn W, Jiang MH, Kim JC and Son Y: A new role of substance $P$ as an injury-inducible messenger for mobilization of CD29(+) stromal-like cells. Nat Med 15: 425-435, 2009.

39. Um J, Jung N, Chin S, Cho Y, Choi S and Park KS: Substance $P$ enhances EPC mobilization for accelerated wound healing. Wound Repair Regen 24: 402-410, 2016.

40. Dubon MJ and Park KS: The mechanisms of substance P-mediated migration of bone marrow-derived mesenchymal stem cell-like ST2 cells. Int J Mol Med 37: 1105-1111, 2016.

41. Sohn SJ: Substance P upregulates osteoclastogenesis by activating nuclear factor kappa B in osteoclast precursors. Acta Otolaryngol 125: 130-133, 2005.

42. Fukuda A, Goto T, Kuroishi KN, Gunjigake KK, Kataoka S, Kobayashi S and Yamaguchi K: Hemokinin-1 competitively inhibits substance P-induced stimulation of osteoclast formation and function. Neuropeptides 47: 251-259, 2013.

43. Sang X, Wang Z, Shi P, Li Y and Cheng L: CGRP accelerates the pathogenesis of neurological heterotopic ossification following spinal cord injury. Artif Cells Nanomed Biotechnol 47: 2569-2574, 2019

44. Wang L, Shi X, Zhao R, Halloran BP, Clark DJ, Jacobs CR and Kingery WS: Calcitonin-gene-related peptide stimulates stromal cell osteogenic differentiation and inhibits RANKL induced NF-kappaB activation, osteoclastogenesis and bone resorption. Bone 46: 1369-1379, 2010. 
45. He H, Chai J, Zhang S, Ding L, Yan P, Du W and Yang Z: CGRP may regulate bone metabolism through stimulating osteoblast differentiation and inhibiting osteoclast formation. Mol Med Rep 13: 3977-3984, 2016.

46. Zhang Q, Guo Y, Yu H, Tang Y, Yuan Y, Jiang Y, Chen H, Gong P and Xiang L: Receptor activity-modifying protein 1 regulates the phenotypic expression of BMSCs via the Hippo/Yap pathway. J Cell Physiol 234: 13969-13976, 2019.

47. Mishima T, Ito Y, Hosono K, Tamura Y, Uchida Y, Hirata M, Suzsuki T, Amano H, Kato S, Kurihara Y, et al: Calcitonin gene-related peptide facilitates revascularization during hindlimb ischemia in mice. Am J Physiol Heart Circ Physiol 300: H431-H439, 2011.

48. Zhang S, Li J, Jiang H, Gao Y, Cheng P, Cao T, Li D, Wang J, Song Y, Liu B, et al: Dorsal root ganglion maintains stemness of bone marrow mesenchymal stem cells by enhancing autophagy through the AMPK/mTOR pathway in a coculture system. Stem Cells Int 2018: 8478953, 2018.

49. Zhou Z, Hu CP, Wang CJ, Li TT, Peng J and Li YJ: Calcitonin gene-related peptide inhibits angiotensin II-induced endothelial progenitor cells senescence through up-regulation of klotho expression. Atherosclerosis 213: 92-101, 2010.

50. Blackwell KA, Raisz LG and Pilbeam CC: Prostaglandins in bone: Bad cop, good cop? Trends Endocrinol Metab 21: 294-301, 2010.

51. Guo C, Yuan L, Wang JG, Wang F, Yang XK, Zhang FH Song JL, Ma XY, Cheng Q and Song GH: Lipopolysaccharide (LPS) induces the apoptosis and inhibits osteoblast differentiation through JNK pathway in MC3T3-E1 cells. Inflammation 37: 621-631, 2014

52. Zhou Y, Zhang H, Zhang G, He Y, Zhang P, Sun Z, Gao Y and Tan Y: Calcitonin generelated peptide reduces Porphyromonas gingivalis LPSinduced TNF $\alpha$ release and apoptosis in osteoblasts. Mol Med Rep 17: 3246-3254, 2018.

53. Loi F, Córdova LA, Zhang R, Pajarinen J, Lin TH, Goodman SB and Yao Z: The effects of immunomodulation by macrophage subsets on osteogenesis in vitro. Stem Cell Res Ther 7: 15, 2016.

54. Hong HS and Son Y: Substance P ameliorates collagen II-induced arthritis in mice via suppression of the inflammatory response. Biochem Biophys Res Commun 453: 179-184, 2014.

55. Liu X, Liu H, Xiong Y, Yang L, Wang C, Zhang R and Zhu X: Postmenopausal osteoporosis is associated with the regulation of SP, CGRP, VIP, and NPY. Biomed Pharmacother 104: 742-750, 2018.

56. Webster JM, Fenton CG, Langen R and Hardy RS: Exploring the interface between inflammatory and therapeutic glucocorticoid induced bone and muscle loss. Int J Mol Sci 20: 5768, 2019

57. Chen H, Hu B, Lv X, Zhu S, Zhen G, Wan M, Jain A, Gao B Chai Y, Yang M, et al: Prostaglandin E2 mediates sensory nerve regulation of bone homeostasis. Nat Commun 10: 181, 2019.

58. Grässel SG: The role of peripheral nerve fibers and their neurotransmitters in cartilage and bone physiology and pathophysiology. Arthritis Res Ther 16: 485, 2014.

59. Jikko A, Murakami H, Yan W, Nakashima K, Ohya Y, Satakeda $H$ Noshiro M, Kawamoto T, Nakamura S, Okada Y, et al: Effects of cyclic adenosine 3',5'-monophosphate on chondrocyte terminal differentiation and cartilage-matrix calcification. Endocrinology 137: 122-128, 1996.

60. Buma P, Verschuren C, Versleyen D, Van der Kraan P and Oestreicher AB: Calcitonin gene-related peptide, substance $\mathrm{P}$ and GAP-43/B-50 immunoreactivity in the normal and arthrotic knee joint of the mouse. Histochemistry 98: 327-339, 1992

61. Salo PT, Hogervorst T, Seerattan RA, Rucker D and Bray RC: Selective joint denervation promotes knee osteoarthritis in the aging rat. J Orthop Res 20: 1256-1264, 2002.

62. Eitner A, Pester J, Nietzsche S, Hofmann GO and Schaible HG The innervation of synovium of human osteoarthritic joints in comparison with normal rat and sheep synovium. Osteoarthritis Cartilage 21: 1383-1391, 2013.

63. Howard MR, Millward-Sadler SJ, Vasilliou AS, Salter DM and Quinn JP: Mechanical stimulation induces preprotachykinin gene expression in osteoarthritic chondrocytes which is correlated with modulation of the transcription factor neuron restrictive silence factor. Neuropeptides 42: 681-686, 2008.

64. Muschter D, Fleischhauer L, Taheri S, Schilling AF, Clausen-Schaumann $\mathrm{H}$ and Grässel S: Sensory neuropeptides are required for bone and cartilage homeostasis in a murine destabilization-induced osteoarthritis model. Bone 133: 115181, 2020.

65. Kim SJ, Kim JE, Kim SH, Kim SJ, Jeon SJ, Kim SH and Jung Y: Therapeutic effects of neuropeptide substance $\mathrm{P}$ coupled with self-assembled peptide nanofibers on the progression of osteoarthritis in a rat model. Biomaterials 74: 119-130, 2016.
66. Nishiura T and Abe K: Alpha1-adrenergic receptor stimulation induces the expression of receptor activator of nuclear factor kappaB ligand gene via protein kinase $\mathrm{C}$ and extracellular signal-regulated kinase pathways in MC3T3-E1 osteoblast-like cells. Arch Oral Biol 52: 778-785, 2007.

67. Zhu Y, Ma Y and Elefteriou F: Cortical bone is an extraneuronal site of norepinephrine uptake in adult mice. Bone Rep 9: 188-198, 2018.

68. Mitchell J, Lai LP, Peralta F, Xu Y and Sugamori K: $\beta 2$-adrenergic receptors inhibit the expression of collagen type II in growth plate chondrocytes by stimulating the AP-1 factor Jun-B. Am J Physiol Endocrinol Metab 300: E633-E639, 2011.

69. Liang H, Zeng Y, Feng Y, Wu H, Gong P and Yao Q: Selective $\beta 2$-adrenoreceptor signaling regulates osteoclastogenesis via modulating RANKL production and neuropeptides expression in osteocytic MLO-Y4 cells. J Cell Biochem: Nov 1, 2018 doi: 10.1002/jcb.27998. Online ahead of print.

70. Fonseca TL, Jorgetti V, Costa CC, Capelo LP, Covarrubias AE, Moulatlet AC, Teixeira MB,Hesse E, Morethson P,BeberEH, et al: Double disruption of $\alpha 2 \mathrm{~A}$ - and $\alpha 2 \mathrm{C}$-adrenoceptors results in sympathetic hyperactivity and high-bone-mass phenotype. J Bone Miner Res 26: 591-603, 2011.

71. Grässel S and Muschter D: Peripheral nerve fibers and their neurotransmitters in osteoarthritis pathology. Int J Mol Sci 18: 931, 2017.

72. Hamrick MW and Ferrari SL: Leptin and the sympathetic connection of fat to bone. Osteoporos Int 19: 905-912, 2008.

73. Pierroz DD, Bonnet N, Bianchi EN, Bouxsein ML, Baldock PA, Rizzoli R and Ferrari SL: Deletion of $\beta$-adrenergic receptor 1, 2 , or both leads to different bone phenotypes and response to mechanical stimulation. J Bone Miner Res 27: 1252-1262, 2012.

74. Khosla S, Drake MT, Volkman TL, Thicke BS, Achenbach SJ, Atkinson EJ, Joyner MJ, Rosen CJ, Monroe DG and Farr JN: Sympathetic $\beta 1$-adrenergic signaling contributes to regulation of human bone metabolism. J Clin Invest 128: 4832-4842, 2018.

75. Arai M, Sato T, Takeuchi S, Goto S and Togari A: Dose effects of butoxamine, a selective $\beta 2$-adrenoceptor antagonist, on bone metabolism in spontaneously hypertensive rat. Eur J Pharmacol 701: 7-13, 2013.

76. Farr JN, Charkoudian N, Barnes JN, Monroe DG, McCready LK, Atkinson EJ, Amin S, Melton LJ III, Joyner MJ and Khosla S: Relationship of sympathetic activity to bone microstructure, turnover, and plasma osteopontin levels in women. J Clin Endocrinol Metab 97: 4219-4227, 2012.

77. Ma Y, Krueger JJ, Redmon SN, Uppuganti S, Nyman JS, Hahn MK and Elefteriou F: Extracellular norepinephrine clearance by the norepinephrine transporter is required for skeletal homeostasis. J Biol Chem 288: 30105-30113, 2013.

78. Bajayo A, Bar A, Denes A, Bachar M, Kram V, Attar-Namdar M, Zallone A, Kovács KJ, Yirmiya R and Bab I: Skeletal parasympathetic innervation communicates central IL-1 signals regulating bone mass accrual. Proc Natl Acad Sci USA 109: 15455-15460, 2012.

79. Du Z, Wang L, Zhao Y, Cao J, Wang T, Liu P, Zhang Y, Yang X, Cheng X, Liu B and Lei D: Sympathetic denervation-induced MSC mobilization in distraction osteogenesis associates with inhibition of MSC migration and osteogenesis by norepinephrine/adrb3. PLoS One 9: e105976, 2014.

80. Méndez-Ferrer S, Michurina TV, Ferraro F, Mazloom AR Macarthur BD, Lira SA, Scadden DT, Ma'ayan A, Enikolopov GN and Frenette PS: Mesenchymal and haematopoietic stem cells form a unique bone marrow niche. Nature 466: 829-834, 2010.

81. Wu B, Wang L, Yang X, Mao M, Ye C, Liu P, Yang Z, Yang X, Lei D and Zhang C: Norepinephrine inhibits mesenchymal stem cell chemotaxis migration by increasing stromal cell-derived factor-1 secretion by vascular endothelial cells via NE/abrd3/JNK pathway. Exp Cell Res 349: 214-220, 2016.

82. Matic I, Matthews BG, Kizivat T, Igwe JC, Marijanovic I, Ruohonen ST, Savontaus E, Adams DJ and Kalajzic I: Bone-specific overexpression of NPY modulates osteogenesis. J Musculoskelet Neuronal Interact 12: 209-218, 2012.

83. Parker RM and Herzog H: Regional distribution of Y-receptor subtype mRNAs in rat brain. Eur J Neurosci 11: 1431-1448, 1999.

84. Lee NJ, Doyle KL, Sainsbury A, Enriquez RF, Hort YJ, Riepler SJ, Baldock PA and Herzog H: Critical role for Y1 receptors in mesenchymal progenitor cell differentiation and osteoblast activity. J Bone Miner Res 25: 1736-1747, 2010.

85. Driessler F and Baldock PA: Hypothalamic regulation of bone. J Mol Endocrinol 45: 175-181, 2010. 
86. Sousa DM, Baldock PA, Enriquez RF, Zhang L, Sainsbury A, Lamghari $M$ and Herzog H: Neuropeptide Y Y1 receptor antagonism increases bone mass in mice. Bone 51: 8-16, 2012.

87. Baldock PA, Allison SJ, Lundberg P, Lee NJ, Slack K, Lin EJ Enriquez RF, McDonald MM, Zhang L, During MJ, et al: Novel role of $\mathrm{Y} 1$ receptors in the coordinated regulation of bone and energy homeostasis. J Biol Chem 282: 19092-19102, 2007.

88. Lee NJ, Nguyen AD, Enriquez RF, Doyle KL, Sainsbury A Baldock PA and Herzog H: Osteoblast specific Y1 receptor deletion enhances bone mass. Bone 48: 461-467, 2011.

89. Lundberg P, Allison SJ, Lee NJ, Baldock PA, Brouard N, Rost S, Enriquez RF, Sainsbury A, Lamghari M, Simmons P, et al: Greater bone formation of $\mathrm{Y} 2$ knockout mice is associated with increased osteoprogenitor numbers and altered Y1 receptor expression. J Biol Chem 282: 19082-19091, 2007.

90. Shi YC, Lin S, Castillo L, Aljanova A, Enriquez RF Nguyen AD, Baldock PA, Zhang L, Bijker MS, Macia L, et al: Peripheral-specific y2 receptor knockdown protects mice from high-fat diet-induced obesity. Obesity (Silver Spring) 19: 2137-2148, 2011.

91. Khor EC, Yulyaningsih E, Driessler F, Kovaĉić N, Wee NKY, Kulkarni RN, Lee NJ, Enriquez RF, Xu J, Zhang L, et al: The y6 receptor suppresses bone resorption and stimulates bone formation in mice via a suprachiasmatic nucleus relay. Bone 84 139-147, 2016.

92. Jiang ZQ, Zhou YL, Chen X, Li LY, Liang SY, Lin S and Shu MQ: Different effects of neuropeptide Y on proliferation of vascular smooth muscle cells via regulation of Geminin. Mol Cell Biochem 433: 205-211, 2017.

93. Alasvand M, Rashidi B, Javanmard SH, Akhavan MM and Khazaei M: Effect of blocking of neuropeptide Y Y2 receptor on tumor angiogenesis and progression in normal and diet-induced obese C57BL/6 mice. Glob J Health Sci 7: 69-78, 2015.

94. Fetissov SO, Xu ZQ, Byrne LC, Hassani H, Ernfors P and Hökfelt T: Neuropeptide y targets in the hypothalamus: Nitric oxide synthesizing neurones express Y1 receptor. J Neuroendocrinol 15: 754-760, 2003.

95. Lai LP and Mitchell J: Beta2-adrenergic receptors expressed on murine chondrocytes stimulate cellular growth and inhibit the expression of Indian hedgehog and collagen type X. J Cell Biochem 104: 545-553, 2008.

96. Martin LJ, Piltonen MH, Gauthier J, Convertino M, Acland EL, Dokholyan NV, Mogil JS, Diatchenko L and Maixner W: Differences in the antinociceptive effects and binding properties of propranolol and bupranolol enantiomers. J Pain 16 1321-1333, 2015.

97. Light KC, Bragdon EE, Grewen KM, Brownley KA, Girdler SS and Maixner W: Adrenergic dysregulation and pain with and without acute beta-blockade in women with fibromyalgia and temporomandibular disorder. J Pain 10: 542-552, 2009.

98. Valdes AM, Abhishek A, Muir K, Zhang W, Maciewicz RA and Doherty M: Association of beta-blocker use with less prevalent joint pain and lower opioid requirement in people with osteoarthritis. Arthritis Care Res (Hoboken) 69: 1076-1081, 2017.

99. Kang X, Qian Z, Liu J, Feng D, Li H, Zhang Z, Jin X, Ma Z, $\mathrm{Xu}$ M, Li F, et al: Neuropeptide Y acts directly on cartilage homeostasis and exacerbates progression of osteoarthritis through NPY2R. J Bone Miner Res 35: 1375-1384, 2020.

100. Wang L, Zhang L, Pan H, Peng S, Lv M and Lu WW: Levels of neuropeptide $\mathrm{Y}$ in synovial fluid relate to pain in patient with knee osteoarthritis. BMC Musculoskelet Disord 15: 319 , 2014.

101. Kuo LE, Kitlinska JB, Tilan JU, Li L, Baker SB, Johnson MD, Lee EW, Burnett MS, Fricke ST, Kvetnansky R, et al: Neuropeptide Y acts directly in the periphery on fat tissue and mediates stress-induced obesity and metabolic syndrome. Nat Med 13: 803-811, 2007.

102. Worzfeld T and Offermanns S: Semaphorins and plexins as therapeutic targets. Nat Rev Drug Discov 13: 603-621, 2014

103. Gomez C, Burt-Pichat B, Mallein-Gerin F, Merle B, Delmas PD, Skerry TM, Vico L, Malaval L and Chenu C: Expression of Semaphorin-3A and its receptors in endochondral ossification: Potential role in skeletal development and innervation. Dev Dyn 234: 393-403, 2005

104. Li Y, Yang L, He S and Hu J: The effect of semaphorin 3A on fracture healing in osteoporotic rats. J Orthop Sci 20: 1114-1121, 2015

105. Hayashi M, Nakashima T, Taniguchi M, Kodama T, Kumanogoh A and Takayanagi H: Osteoprotection by semaphorin 3A. Nature 485: 69-74, 2012.
106. Kular J, Tickner J, Chim SM and Xu J: An overview of the regulation of bone remodelling at the cellular level. Clin Biochem 45 863-873, 2012.

107. Sun J, Wei X, Wang Z, Liu Y, Lu J, Lu Y, Cui M, Zhang X and Li F: Inflammatory milieu cultivated Sema3A signaling promotes chondrocyte apoptosis in knee osteoarthritis. J Cell Biochem 119: 2891-2899, 2018.

108. Dénes A, Boldogkoi Z, Uhereczky G, Hornyák A, Rusvai M, Palkovits $\mathrm{M}$ and Kovács KJ: Central autonomic control of the bone marrow: Multisynaptic tract tracing by recombinant pseudorabies virus. Neuroscience 134: 947-963, 2005.

109. Sharan K and Yadav VK: Hypothalamic control of bone metabolism. Best Pract Res Clin Endocrinol Metab 28: 713-723, 2014

110. Spiegelman BM and Flier JS: Obesity and the regulation of energy balance. Cell 104: 531-543, 2001.

111. Camerino C, Zayzafoon M, Rymaszewski M, Heiny J, Rios M and Hauschka PV: Central depletion of brain-derived neurotrophic factor in mice results in high bone mass and metabolic phenotype. Endocrinology 153: 5394-5405, 2012.

112. Elefteriou F, Ahn JD, Takeda S, Starbuck M, Yang X, Liu X, Kondo H, Richards WG, Bannon TW, Noda M, et al: Leptin regulation of bone resorption by the sympathetic nervous system and CART. Nature 434: 514-520, 2005.

113. Yadav VK, Oury F, Suda N, Liu ZW, Gao XB, Confavreux C, Klemenhagen KC, Tanaka KF, Gingrich JA, Guo XE, et al: A serotonin-dependent mechanism explains the leptin regulation of bone mass, appetite, and energy expenditure. Cell 138 976-989, 2009.

114. Mercer JG, Hoggard N, Williams LM, Lawrence CB, Hannah LT, Morgan PJ and Trayhurn P: Coexpression of leptin receptor and preproneuropeptide Y mRNA in arcuate nucleus of mouse hypothalamus. J Neuroendocrinol 8: 733-735, 1996.

115. Hamrick MW, Della-Fera MA, Choi YH, Pennington C, Hartzell D and Baile CA: Leptin treatment induces loss of bone marrow adipocytes and increases bone formation in leptindeficient ob/ob mice. J Bone Miner Res 20: 994-1001, 2005.

116. Lamghari M, Tavares L, Camboa N and Barbosa MA: Leptin effect on RANKL and OPG expression in MC3T3-E1 osteoblasts. J Cell Biochem 98: 1123-1129, 2006.

117. Turner RT, Kalra SP, Wong CP, Philbrick KA, Lindenmaier LB, Boghossian S and Iwaniec UT: Peripheral leptin regulates bone formation. J Bone Miner Res 28: 22-34, 2013.

118. Hamrick MW, Pennington C, Newton D, Xie D and Isales C: Leptin deficiency produces contrasting phenotypes in bones of the limb and spine. Bone 34: 376-383, 2004.

119. Ealey KN, Fonseca D, Archer MC and Ward WE: Bone abnormalities in adolescent leptin-deficient mice. Regul Pept 136 9-13, 2006

120. Yu B, Jiang K, Chen B, Wang H, Li X and Liu Z: Leptin differentially regulates chondrogenesis in mouse vertebral and tibial growth plates. BMC Musculoskelet Disord 18: 235, 2017.

121. Yan M, Zhang J, Yang H and Sun Y: The role of leptin in osteoarthritis. Medicine (Baltimore) 97: e0257, 2018.

122. Sandell LJ: Obesity and osteoarthritis: Is leptin the link? Arthritis Rheum 60: 2858-2860, 2009.

123. Yaykasli KO, Hatipoglu OF, Yaykasli E, Yildirim K, Kaya E, Ozsahin M, Uslu M and Gunduz E Leptin induces ADAMTS-4, ADAMTS-5, and ADAMTS-9 genes expression by mitogen-activated protein kinases and NF- $\mathrm{KB}$ signaling pathways in human chondrocytes. Cell Biol Int 39: 104-112, 2015

124. Su YP, Chen CN, Huang KC, Chang HI, Lee KC, Lo CM and Chang SF: Leptin induces MMP1/13 and ADAMTS 4 expressions through bone morphogenetic protein-2 autocrine effect in human chondrocytes. J Cell Biochem 119: 3716-3724, 2018.

125. Chang SF, Hsieh RZ, Huang KC, Chang CA, Chiu FY, Kuo HC Chen $\mathrm{CN}$ and Su YP: Upregulation of bone morphogenetic protein-2 synthesis and consequent collagen II expression in leptin-stimulated human chondrocytes. PLoS One 10: e0144252, 2015.

126. Zhao X, Dong Y, Zhang J, Li D, Hu G, Yao J, Li Y, Huang P, Zhang M, Zhang J, et al: Leptin changes differentiation fate and induces senescence in chondrogenic progenitor cells. Cell Death Dis 7: e2188, 2016.

127. Liu Q, Lei L, Yu T, Jiang T and Kang Y: Effect of brain-derived neurotrophic factor on the neurogenesis and osteogenesis in bone engineering. Tissue Eng Part A 24: 1283-1292, 2018.

128. Foudah D, Redondo J, Caldara C, Carini F, Tredici G and Miloso M: Human mesenchymal stem cells express neuronal markers after osteogenic and adipogenic differentiation. Cell Mol Biol Lett 18: 163-186, 2013 
129. Parfejevs V, Debbache J, Shakhova O, Schaefer SM, Glausch M Wegner M, Suter U, Riekstina U, Werner S and Sommer L: Injury-activated glial cells promote wound healing of the adult skin in mice. Nat Commun 9: 236, 2018.

130. Zhang Z, Zhang Y, Zhou Z, Shi H, Qiu X, Xiong J and Chen Y: BDNF regulates the expression and secretion of VEGF from osteoblasts via the TrkB/ERK1/2 signaling pathway during fracture healing. Mol Med Rep 15: 1362-1367, 2017.

131. Kilian O, Hartmann S, Dongowski N, Karnati S, Baumgart-VogtE, Härtel FV, Noll T, Schnettler R and Lips KS: BDNF and its TrkB receptor in human fracture healing. Ann Anat 196: 286-295, 2014.

132. Su YW, Chung R, Ruan CS, Chim SM, Kuek V, Dwivedi PP, Hassanshahi M, Chen KM, Xie Y, Chen L, et al: Neurotrophin-3 induces BMP-2 and VEGF activities and promotes the bony repair of injured growth plate cartilage and bone in rats. J Bone Miner Res 31: 1258-1274, 2016.

133. Walsh DA, McWilliams DF, Turley MJ, Dixon MR, Fransès RE, Mapp PI and Wilson D: Angiogenesis and nerve growth factor at the osteochondral junction in rheumatoid arthritis and osteoarthritis. Rheumatology (Oxford) 49: 1852-1861, 2010.

134. Takeda K, Shiba H, Mizuno N, Hasegawa N, Mouri Y, Hirachi A, Yoshino H, Kawaguchi $\mathrm{H}$ and Kurihara H: Brain-derived neurotrophic factor enhances periodontal tissue regeneration. Tissue Eng 11: 1618-1629, 2005.

135. Zhang J, Wang L, Cao H, Chen N, Yan B, Ao X, Zhao H, Chu J, Huang $M$ and Zhang Z: Neurotrophin-3 acts on the endothelial-mesenchymal transition of heterotopic ossification in rats J Cell Mol Med 23: 2595-2609, 2019.

136. Shen L, Zeng W, Wu YX, Hou CL, Chen W, Yang MC, Li L, Zhang YF and Zhu CH: Neurotrophin-3 accelerates wound healing in diabetic mice by promoting a paracrine response in mesenchymal stem cells. Cell Transplant 22: 1011-1021, 2013 .
137. Caporali A and Emanueli C: Cardiovascular actions of neurotrophins. Physiol Rev 89: 279-308, 2009.

138. Itoyama T, Yoshida S, Tomokiyo A, Hasegawa D, Hamano S, Sugii H, Ono T, Fujino S and Maeda H: Possible function of GDNF and Schwann cells in wound healing of periodontal tissue. J Periodontal Res: Jun 20, 2020 doi: 10.1111/jre.12774. (Online Ahead of Print).

139. Yajima S, Lammers CH, Lee SH, Hara Y, Mizuno K and Mouradian MM: Cloning and characterization of murine glial cell-derived neurotrophic factor inducible transcription factor (MGIF). J Neurosci 17: 8657-8666, 1997.

140. Chen Z, Li W, Wang H, Wan C, Luo D, Deng S, Chen H and Chen S: Klf10 regulates odontoblast differentiation and mineralization via promoting expression of dentin matrix protein 1 and dentin sialophosphoprotein genes. Cell Tissue Res 363 . 385-398, 2016.

141. Subramaniam M, Pitel KS, Withers SG, Drissi H and Hawse JR: TIEG1 enhances Osterix expression and mediates its induction by TGF $\beta$ and BMP2 in osteoblasts. Biochem Biophys Res Commun 470: 528-533, 2016.

142. Gale Z, Cooper PR and Scheven BA: Glial cell line-derived neurotrophic factor influences proliferation of osteoblastic cells. Cytokine 57: 276-281, 2012.

This work is licensed under a Creative Commons Attribution-NonCommercial-NoDerivatives 4.0 International (CC BY-NC-ND 4.0) License. 